\title{
Reinforcing Effects of Near Wins in Extinction and Concurrent- Chains Procedures
}

\author{
Nathaniel Rice
}

Follow this and additional works at: https://researchrepository.wvu.edu/etd

\section{Recommended Citation}

Rice, Nathaniel, "Reinforcing Effects of Near Wins in Extinction and Concurrent-Chains Procedures" (2014). Graduate Theses, Dissertations, and Problem Reports. 7240.

https://researchrepository.wvu.edu/etd/7240

This Dissertation is protected by copyright and/or related rights. It has been brought to you by the The Research Repository @ WVU with permission from the rights-holder(s). You are free to use this Dissertation in any way that is permitted by the copyright and related rights legislation that applies to your use. For other uses you must obtain permission from the rights-holder(s) directly, unless additional rights are indicated by a Creative Commons license in the record and/ or on the work itself. This Dissertation has been accepted for inclusion in WVU Graduate Theses, Dissertations, and Problem Reports collection by an authorized administrator of The Research Repository @ WVU.

For more information, please contact researchrepository@mail.wvu.edu. 
Reinforcing Effects of Near Wins in Extinction and Concurrent-Chains Procedures

Nathaniel Rice

\begin{abstract}
Dissertation submitted
to the Eberly College of Arts and Sciences

at West Virginia University
\end{abstract}

in partial fulfillment of the requirements for the degree of

Doctor of Philosophy in

Psychology

Elizabeth Kyonka, Ph.D., Chair

Michael Perone, Ph.D.

Regina Carroll, Ph.D.

Daniel W. McNeil, Ph.D.

Matthew Wilson, Ph.D.

Department of Psychology

Morgantown, West Virginia

2014

Keyword: gambling; concurrent chains; extinction; conditioned reinforcer; near win; near loss Copyright 2014 Nathaniel Rice 


\begin{abstract}
Reinforcing Effects of Near Wins in Extinction and Concurrent-Chains Procedures
\end{abstract}

\title{
Nathaniel Rice
}

In slot-machine play, near wins are stimuli that approximate winning stimuli but deliver no reinforcement (e.g., two winning symbols and a losing symbol). This dissertation developed an animal model of slot-machine gambling and investigated the conditioned reinforcing effects of near wins in extinction and preference assessments. In three experiments, keys were illuminated red or green following pecks in a three-stimulus sequence. Three successive red stimuli was a win, three green lights was a clear loss, and two red stimuli followed by a green was a near win. Following the three-stimulus sequence, a white "collect" key was illuminated for $5 \mathrm{~s}$. A single peck was required during this interval for food to be delivered on winning trials. In Experiment 1, pigeons were trained using this procedure then switched to extinction. Near-win trials were either present or absent during extinction. The presence of near-win trials did not alter the amount of trials completed in extinction. In Experiment 2, pigeons were trained using this procedure embedded within concurrent chains. Pigeons had the ability to respond for access to a component that delivered only wins, only wins and clear losses, or all three trial types.

Reinforcer access was systematically varied between these components. Pigeons allocated more responses to the component that presented near wins than the schedule that only delivered wins. In Experiment 3, the same concurrent-chains procedure was used and the probability of a nearwin trial was systematically altered. Response allocation to the component with near wins increased as the probability of a near-win trial increased. These experiments demonstrated that near-win trials affect choosing to gamble and preference between gambling options. 


\section{Acknowledgements}

I would like to thank Elizabeth Kyonka, Michael Perone, Regina Carroll, Dan McNeil, and Matthew Wilson for serving as members of my dissertation committee and for their valuable

input and comments in preparing this manuscript. I am especially thankful to Liz for serving as the chair of my committee and as my advisor. 


\section{Table of Contents}

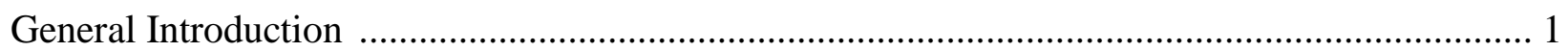

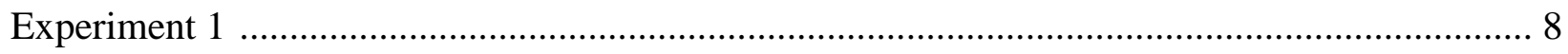

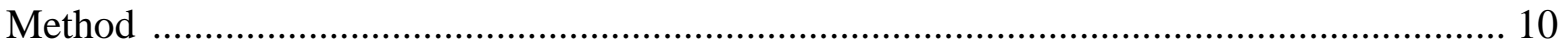

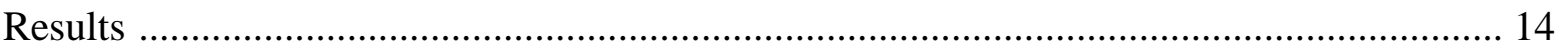

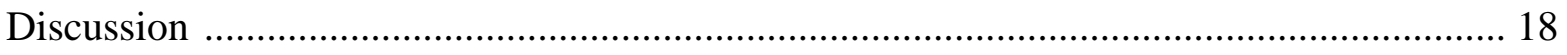

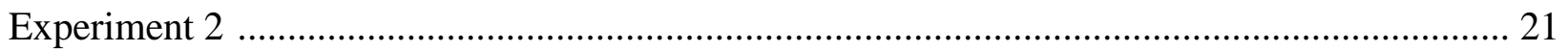

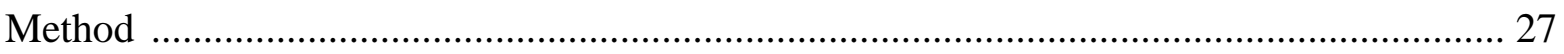

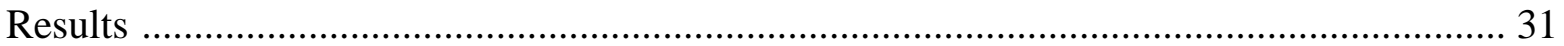

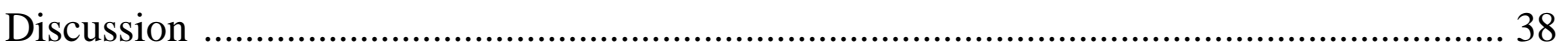

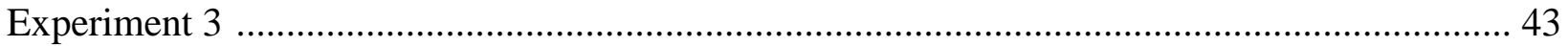

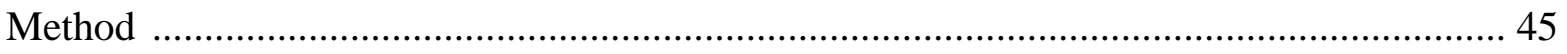

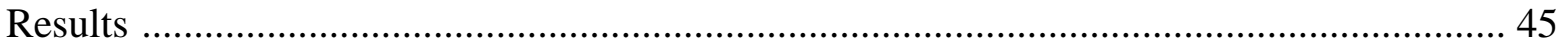

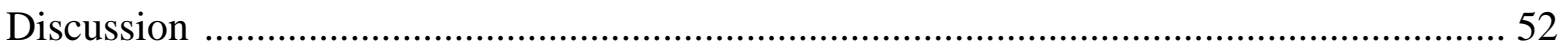

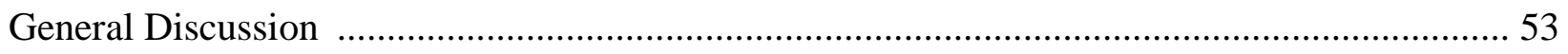

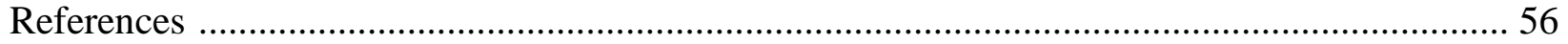

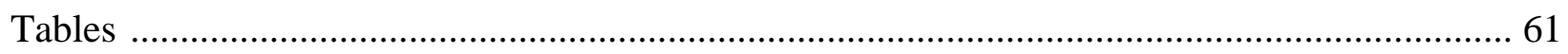

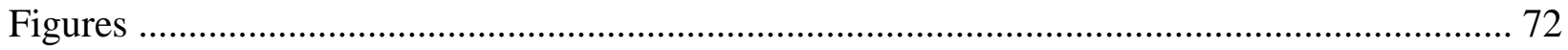


Reinforcing Effects of Near Wins in Extinction and Concurrent Chains Procedures Gambling is a pervasive behavior that generated \$37.34 billion in the United Stated in 2012 (American Gaming Association, 2013a). While the majority of individuals who gamble do so recreationally, 1-3\% are classified as problem gamblers (Shaffer, Hall, \& Vander Bilt, 1999; Welte, Barnes, Tidwell, \& Hoffman, 2008). Problem gambling is defined as excessive gambling that eventually leads to financial and social dysfunction (Raylu \& Oei, 2002). Slot-machine play is of particular interest when studying gambling, as $61 \%$ of casino patrons report that their favorite casino games are electronic gaming machines like slot machines and video poker (American Gaming Association, 2013b). Near wins, a type of outcome that occurs during slotmachine play, are thought to be one of the controlling factors for both recreational and problem gambling. The current experiments investigated the stimulus control properties of near wins using pigeons to determine their conditioned reinforcing effects, which may help explain how near wins control gambling behavior in humans.

In typical slot-machine play, gamblers are required to wager some monetary amount at each opportunity to play. After a wager is made, reels of symbols are "spun" and eventually settle into an arrangement of three or more stimuli in a given row. Winning occurs when the row of stimuli match and losing occurs when they do not match. The majority of games played end in a loss and over a long period of time, gamblers are expected to lose money through slotmachine play.

Near wins are a type of outcome that occurs during slot-machine play and are visually similar to a win but no reinforcement is ever delivered on these trials. Near wins are comprised of two similar stimuli and a third, dissimilar stimulus (e.g., two cherries and a lemon). 
Because of the relative visual similarity between wins and near wins, near wins may encourage continued betting (e.g., Côté, Caron, Aubert, Desrochers, \& Ladouceur, 2003). In fact, human participants who gambled in a laboratory setting reported that near wins were more similar to wins than losses (Dixon \& Schreiber, 2004). Skinner (1953, p. 397) suggested that near wins functioned as reinforcers and because they can be delivered at no cost to the casino, they are a financially expedient means of prolonging gambling among patrons.

Near wins are of interest due to their supposed ability to encourage continued betting during a period of prolonged loss. Experimentally, these prolonged losses represent periods of extinction. Extinction refers to a time when reinforcement is made unavailable. For gamblers, this means that their responses (i.e., gambling) are not reinforced because winning trials are not contacted and therefore the gambler only experiences losses. During these periods of extinction, gamblers are continuing to make wagers and therefore losing larger sums of money, an outcome of interest since problem gamblers will often gamble to excess and extreme monetary loss.

Human gamblers have been required to play a slot machine in several laboratory experiments. In one such experiment, Côté and colleagues (2003) had human participants play a slot machine for a certain number of bets as baseline training. All winning trials were removed following baseline training, mimicking the periods of extinction that can occur during normal slot-machine play, and participants were instructed to continue playing as long as they liked. Under these extinction conditions, one group of participants continued to receive near wins, while another group experienced only losses. Since wins could never occur in the extinction condition, it was optimal for the subjects to stop gambling - continued betting led only to further monetary loss. The continued presentation of near wins increased the time spent gambling compared to when near wins were absent. 
Kassinove and Schare (2001) conducted a similar study with an extinction test.

However, instead of comparing two groups with and without near wins, Kassinove and Schare instead compared across three different near-win frequencies: $15 \%, 30 \%$, and $45 \%$. These frequencies were the relative occurrence of near-win trials during slot-machine play. The authors found that the $30 \%$ group played for the longest during extinction. While it is clear that near-win trials affect gambling, there exists relatively little literature examining these effects outside of extinction. The current experiments were arranged to extend our knowledge of nearwin effects in extinction using a different approach to the extinction test as well as determine how near wins affect the choice to gamble outside of extinction.

\section{Animal Models of Gambling}

Using human participants to study gambling poses ethical and pragmatic concerns that can be minimized or eliminated by using animal models (Madden, Ewan, \& Lagorio, 2007) Exposing human participants to a potential addictive task requires certain safeguards that are not a concern for animal research. Animals are also more available than human participants for prolonged data collection, which makes certain experimental procedures more feasible in an animal model. Gambling is a complex behavior that may be better understood by analyzing component parts, which requires many sessions of data collection that are not feasible using human subjects. As such, in this dissertation I present results of experiments that used laboratory animals as subjects to study stimulus control and conditioned reinforcement of near wins in isolation. This approach allows for greater experimental control of the gambling context and subject. To date, there have been several successful animal models of gambling and the nearwin effect. 
In a rat model of slot-machine gambling (Peters, Hunt, \& Harper, 2010), one to five chamber lights were lit as a consequence of the rat pressing a lever designed to simulate placing a bet in a slot-machine or video-lottery terminal. Five lights signaled a large win and four lights signaled a small win. All other trials (i.e., one to three lights) resulted in no reinforcement. The authors classified as the presentation of three lights as a near win. After the response phase where lights were illuminated, a second "collect" lever was made available. On a winning trial, pressing the collect lever resulted in reinforcement. Pressing the collect lever during losing trials resulted in a blackout. The latency to start a trial with a lever press was a function of the immediately preceding trial. Latencies were longer after wins than after losses: after a loss, the next trial was started quickly. Latency to initiate a trial after near wins was more similar to wins than losses. In addition, when wins were removed in an extinction condition, responding to the collect lever failed to persist for longer when near wins were present than when they were absent. These findings failed to replicate results shown in human gamblers (e.g., Côté et al., 2003; Kassinove \& Schare, 2001; MacLin, Dixon, Daugherty, \& Small, 2007; Strickland \& Grote, 1967).

In addition to prolonging gambling in extinction, it is important to determine whether near wins affect whether subjects choose to gamble when there are alternative sources of reinforcement available. Gamblers may prefer certain slot machines over others for a variety of reasons and near wins may be a contributing factor. This is especially relevant, given that these same near wins that affect preference may also determine how long a person gambles. Animal models are highly suited to determining changes in preference, given their ability to generate large amounts of data for extended periods of time which would include multiple reversals something that is not as feasible with human participants. 
In a series of experiments, Zentall and colleagues (Laude, Beckman, Daniels, \& Zentall, 2014; Laude, Pattison, \& Zentall, 2012; Laude, Stagner, \& Zentall, 2014; Stagner \& Zentall, 2010) have shown that pigeons prefer probabilistic, gambling-like schedules of reinforcement over schedules where the reinforcer is delivered with certainty. In these experiments, there are typically two possible alternatives available to the pigeons on the left and right side keys. One key leads to certain food $(\mathrm{p}=1)$ and the other key leads to probabilistic food $(\mathrm{p}<1)$. The amount of food on each key varies between experiments, but generally the certain food delivers smaller amounts. However, because the certain food occurs more frequently, this option delivers more food over the course of an entire session and is therefore the choice that maximizes food reinforcement. Essentially, the pigeons are choosing a small amount of certain food versus a large amount of probabilistic food. The large, probabilistic option is gambling-like in the sense that reinforcement comes probabilistically, typically in higher amounts than found elsewhere, but at a lower overall rate when magnitude and probability are both accounted for.

In one experiment using this arrangement, Laude et al. (2014) arranged the side keys as described above - a choice between schedules that yielded small, certain food and large, probabilistic food. Both alternatives were differentially signaled, meaning that the color of the key was associated with a particular outcome (food or no food). Despite the non-probabilistic alternative being the better choice (more food over the course of the session), pigeons selected the probabilistic, gambling-like schedule much more frequently. Near-win trials share many similarities to these trials arranged by Laude et al. Near-win trials are differentially signaled and do not lead to food, but these trials encourage continued gambling.

To evaluate behavioral mechanisms that might produce the observed effects of near win on gambling in humans and lever-pressing in rats, Kyonka, Rice, and Ward (in prep) developed a 
procedure that reproduces some of the stimulus properties of slot-machine play. This procedure can be embedded in other schedules including extinction and concurrent chains, which can be used to assess whether near wins affect resistance to change and choice, respectively, two critical aspects in understanding the stimulus control properties of gambling stimuli. In their procedure, red and green side keys signaled winning and losing stimuli, respectively. The presentation of three red stimuli signaled a win, while all other combinations were a loss. This is similar to a human gambler receiving a match of three cherries (a win), while all other outcomes would be a loss. Following the three-stimulus sequence, a white "collect" key was illuminated on the center key for a period of $5 \mathrm{~s}$. A peck at any point during this 5-s period resulted in food delivery on a winning trial. The presentation of two red stimuli, followed by a green stimulus was a near win in the sense that of all losing trials, it looks the most like a winning trial. In typical slotmachine play, human gamblers are matching any three symbols for a win, while in this procedure only three of a specific stimulus (a red key) led to a win. While this is an appreciable difference, the functional control that near-win trials have using this procedure is similar to those experienced by humans in gambling contexts. As such, this model is excellent for investigating the stimulus control properties of near wins and how they affect persistence in extinction and may influence choice.

Using the procedure described above, Kyonka et al. found that the number of red stimuli shown in the trial determined the probability of a response on the collect key. The more red stimuli shown in a trial, the more likely a response was when the collect-key was presented. In addition, response rates on the collect key when a peck did occur showed the near-win effect, where near-win response rates were equivalent to win response rates and different from all other loss types. This was similar to the findings in other animal models (i.e., Peters et al., 2010) and 
measures of skin conductance in human gamblers (Clark, Crooks, Clarke, Aitken \& Dunn, 2012; Dixon, MacLaren, Jarick, Fugelsang \& Harrigan, 2013). The experiments here used this model in extinction (Experiment 1) and concurrent chains (Experiments 2 and 3) to investigate the reinforcing effects and stimulus control properties of near wins.

If the presence of near wins increases persistence of gambling during extinction, then it is expected that when wins are removed, responding will drop to near-zero levels. That is, the pigeons will eventually stop responding when wins are unavailable, but the presence of near wins may decrease the rate at which this occurs. In addition, this model allows for different measures of responding to be taken, such as response rates, response proportions, and latencies, which may all change independently when wins are removed.

Preference is also an important part of gambling, as human gamblers often have the opportunity to choose if they gamble and what game they play. In addition, problem gamblers often gamble excessively, which could be understood as choosing to gamble when they should instead be choosing to not gamble. Whether near wins affect choice is important as it may influence which games people play and how long they play them. Experiment 1 sought to determine how near wins affected how long gambling persisted in extinction. Experiments 2 and 3 used a concurrent-chains procedure, where measures of preference were obtained in addition to response rates, response proportions, and latencies. This approach demonstrated how near wins affected choosing a gambling over a non-gambling option as well as how near-win probability influenced choice. To date there have been no experiments investigating the role near-win trials have on preference using a concurrent-chains procedure, which is an area of research that is important for a better understanding of how near wins control gambling behavior. 


\section{Experiment 1}

One possible explanation for why near wins affect responding differently than other losses is that near wins function as conditioned reinforcers. Conditioned reinforcement is a phenomenon where stimuli gain reinforcing "value" through association with a reinforcer (Shahan, 2010; Williams, 1994a). In slot-machine play, a near win is never followed by a reinforcer. However, wins are always followed by reinforcers and near wins visually approximate wins. In practice, wins are often signaled by a series of identical images arranged in rows. In such cases, a row of images that are all identical but one is a near win. With exposure to this type of slot-machine gambling, it is possible that visual uniformity acquires conditioned reinforcing value. As highly (but not completely) uniform series, near wins may acquire some conditioned reinforcing value despite never being directly associated with a reinforcer. Experiments investigating conditioned reinforcers have found when food is made unavailable (i.e., an extinction condition), the presence of conditioned reinforcers during this extinction condition lead to prolonged responding (see Williams, 1994b for review). This finding is similar to what has been found with near-wins, in that they prolong gambling when wins have been removed and therefore payout is unavailable (e.g., MacLin et al., 2007).

In extinction procedures, the reinforcer is made unavailable and the typical result is that behavior eventually declines to near-zero or zero levels. The rate of decline in responding is influenced by the rate of reinforcement previously established in that schedule (Nevin, Mandell, \& Atak, 1983; Nevin, 2012). Specifically, richer schedules lead to slower declines in responding when extinction is implemented. The presence of conditioned reinforcers, such as a light or tone that was presented concurrent with food during training and not presented in the absence of food, also causes responding to persist for longer in extinction. When comparisons are made between 
extinction conditions, the number of trials completed across sessions serves as a measure for persistence of responding (Côté et al., 2003; Kassinove \& Schare, 2001); proportion of response rates may also be used to make comparisons across subjects.

Experiments investigating the conditioned reinforcing value of near wins using an extinction test have typically used a between-groups design (e.g., Côté et al., 2003; MacLin et al., 2007). In these previous experiments, separate extinction conditions were arranged such that wins no longer occurred and therefore payout also could not occur. These experiments found that the inclusion of near wins in an extinction condition increased the time spent gambling. That is, participants who experienced a condition with clear losses and near wins but no wins chose to continue gambling for more trials than a participant who only experienced clear losses. The prolonged gambling in the presence of near wins in these laboratory experiments imply that casino gamblers who experience near wins are more likely to continue gambling during periods of extended losses and therefore suffer greater monetary loss.

To better understand how near wins affect the persistence of gambling during an extended series of losses, Experiment 1 investigated the persistence of responding using a within-subject design where near wins were present and absent during extinction. Near wins were present and then absent in alternating extinction conditions separated by baseline conditions where wins were re-presented until response rates returned to baseline levels. Previous studies investigating extinction and near wins have done so without controlling for the number of stimuli presented that could serve as conditioned reinforcers (e.g., MacLin et al., 2007; Peters et al., 2010). In those studies, extinction conditions with near wins presented more stimuli associated with winning trials, which could serve as a possible confound. Whenever near wins produced greater persistence in extinction, it was impossible to distinguish whether the near-win trial 
arrangement was the cause or the number of winning stimuli presented. In Experiment 1, the total number of winning stimuli (i.e., red stimuli) presented in each session was held constant across all conditions. This experimental arrangement separated the possible conditioned reinforcing effects of the number of red stimuli shown in a trial and the specific arrangement of near-win trials.

\section{Method}

\section{Subjects}

Five White Carneau pigeons (Columba livia) of mixed sex, numbered 301, 302, and 401403 , were maintained at $85 \%$ ad libitum weight $\pm 15 \mathrm{~g}$ through appropriate post-session feedings and housed individually in cages with a 12-hr:12-hr light:dark cycle with free access to water. All five pigeons had experience pecking keys for food and were immediately placed into the baseline condition.

\section{Apparatus}

Three operant-conditioning chambers $(25.5 \mathrm{~cm}$ deep x $32 \mathrm{~cm}$ wide $\mathrm{x} 33.5 \mathrm{~cm}$ high) were enclosed in sound-attenuating boxes containing ventilation fans that provided air circulation and white noise. Each chamber contained three keys $24 \mathrm{~cm}$ above the floor arranged in a row $6 \mathrm{~cm}$ apart, a houselight located on the back wall at the top of the chamber, and a grain magazine with a $5.5 \mathrm{~cm} \times 6 \mathrm{~cm}$ aperture centered $5.5 \mathrm{~cm}$ above the floor. The houselight provided general illumination at all times, except during reinforcer delivery, during all phases of the procedure. A force of approximately $0.15 \mathrm{~N}$ was necessary to operate each key. Experimental events were controlled through a computer and MED-PC® interface located in an adjacent room.

\section{Procedure}


Baseline. Each trial consisted of a sample phase and a collect phase. Red and green key colors were winning and losing stimuli, respectively. During each sample phase, red, green or a combination of red and green were presented on a side key in a sequence of three stimulus presentations. Figure 1 illustrates the sequence of events in sample and collect phases of a winning trial. Other trial types differed from wins in the sequence of colors presented in the sample phase. Three red stimuli in a row was a "win" and three green stimuli was a "clear loss". Two red stimuli followed by a green stimulus was a "near win" and one red stimulus followed by two green stimuli was a "loss." These combinations are depicted in Figure 2.

At the beginning of each trial, trial type (i.e., win, near win, loss, or clear loss) was selected without replacement from a list of 40 trials that included 10 of each type. Either the left or right key was illuminated red or green. A single peck to the lighted key was required to progress the three-stimulus sequence in the sample phase. The third peck completed the threestimulus sequence and ended the sample phase, at which time the side key was darkened and the center key was illuminated white, signaling the start of the collect phase. In the collect phase, the center key was presented for $5 \mathrm{~s}$. A single peck was required at any point during the 5-s presentation for food to be delivered on winning trials. Pecks to this key during non-winning trials were recorded but there were no programmed consequences. Food delivery on winning trials consisted of three 1.5 -s hopper presentations separated by a 0.5 -s resetting of the hopper. A 10-s intertrial interval separated each trial. On winning trials, reinforcement time was subtracted from the intertrial interval, so that time from the completion of the collect phase to the start of the next sample phase was held constant at $10 \mathrm{~s}$.

Each session lasted for two hours. Pigeons typically completed 200-350 trials per session. Baseline conditions lasted a minimum of 21 days and a maximum of 30 days or until the 
following stability criteria were met: Separate three-session moving average response rates were calculated for each trial type. Baseline performance was considered stable when the response rate in the last session was neither highest nor lowest across the whole baseline for any of the four trial types. In addition, moving-average response rates for each trial type had to be between $85 \%$ and $115 \%$ of the moving average from the preceding session.

Extinction. When a pigeon's performance stabilized in the baseline condition, that pigeon was switched to an extinction condition. In extinction, all winning trials were removed and food was not available during a session. Within an extinction condition, near-win trials either continued to occur (near wins present) or were removed along with wins (near wins absent). When near wins were present, clear losses were $50 \%$ of the trials, losses were $25 \%$ of the trials, and near wins were $25 \%$ of the trials. When near wins were absent, clear losses were $25 \%$ of the trials and losses were $75 \%$ of the trials. Figure 2 shows the breakdown of trial types for each extinction condition. This breakdown was selected because the number of red lights displayed in sample phases of a block of 40 trials was the same (30) in both conditions. The extinction conditions lasted for a minimum of 2 sessions or a maximum of 8 sessions and were terminated when the response rate on the collect key was no more than $10 \%$ of the baseline response rate for two consecutive sessions or when the total number of trials completed was less than $10 \%$ of the average of the 5 preceding baseline sessions. In other words, extinction was terminated when either response rates or the number of trials completed dropped below $10 \%$ of the preceding baseline.

Pigeons 301 and 401 were assigned to Group A and placed into the near-win present condition first. Pigeons 302, 402 and 403 were assigned to Group B and experienced the nearwin absent condition first. Table 1 shows the arrangement of conditions for the two groups. 
Assignment to group A or B was determined by the pigeons' response rates on win trials during

the $20^{\text {th }}$ baseline session, so that each group had one of the two fastest responders and one of the two slowest responders; the number of trials completed and response rates were comparable across the two groups.

Replications of baseline. After each extinction condition, the baseline condition where winning trials and food were available was reinstated to reestablish baseline response rates to red and green keys. All baseline replications adhered to the baseline stability criteria outlined above.

For four of the five pigeons, baseline response rates did not change across subsequent baseline conditions for any of the trial types. For Pigeon 402, baseline response rates did not return to their pre-extinction levels after the third extinction condition (the second loss-only extinction condition). Instead, after 23 sessions baseline rates were determined to be stable at a new, lower rate. The rate of stabilization is similar to that seen in other pigeons and other baseline conditions in this experiment. To ensure that the baseline used for the final extinction test would persist after extinction, Pigeon 402 was returned to the baseline condition after the final extinction condition. Response rates returned to the new, lower baseline level.

Replications of extinction. After subsequent baseline conditions, pigeons were placed into a replication of the extinction condition. Pigeons that initially were in the near-win present condition were placed into the near-win absent condition and vice versa. This cycle was repeated until the pigeons experienced a total of four extinction conditions - two with near wins present and two with near wins absent. Table 1 shows the number of sessions each pigeon spent in all baseline and extinction conditions. 


\section{Results}

The collect key was presented for $5 \mathrm{~s}$ following the termination of the sample phase and required at least one peck to occur during the interval for food to be accessible following a win. To characterize collect-key responding, the proportion of trials where at least one peck occurred and the number of pecks to the collect key during those trials were calculated. Trials where no peck occurred were scored as omissions; Table 2 shows the total number of omissions per trial type for each baseline condition. Figure 3 shows the proportion of trials where at least one peck occurred during the collect phase collapsed across all baseline conditions. Past research using this procedure (Kyonka, Rice, \& Ward, in prep) found that the number of red stimuli shown in the sample phase determined the probability of a collect-key peck. The more like a win a trial was, the more likely a collect-key peck. This same result was obtained for all subjects, where the proportion of trials with a collect-key peck increases as a function of red stimuli shown in the sample phase.

To quantify the effect of trial type on proportions of trials with a collect-key response, a repeated-measures analysis of variance (ANOVA) was conducted using baseline condition and trial type as within-subject factors. There was no main effect of baseline condition $(p=.380)$, indicating that the proportion of trials with a collect-key response did not vary across the separate baseline conditions. There was a difference in response proportions as a function of trial type, $F(3,12)=369.41, p<.001$, as was evident from visual inspection. Bonferroni posthoc analyses revealed that proportions on clear loss $(M=.04, S E=.01)$ and loss trials $(M=.081$, $S E=.02)$ were not significantly different. Proportions from near-win $(M=.27, S E=.05)$ and win trials $(M=.996, S E=.003)$ were significantly different from all other trial types. These findings corroborated visual inspection, in that proportion of trials with a collect-key response 
were highest for wins trials, then near-win trials, and finally loss and clear-loss trials were the lowest. While response proportions on near-win trials were significantly different from win trials, they were also significantly different from other loss trial types, which indicates that nearwin trials may function differently than other losses.

Response rates on the collect key were calculated as the number of pecks that occurred during the collect phase. Only trials where at least one collect-key peck occurred were included in the analysis. Figure 4 displays the mean number of pecks per collect phase as a function of trial type for all pigeons. These response rates were obtained by calculating the mean of the last five sessions of all baseline conditions. Win response rates were highest among all of the subjects. Interestingly, response rates on loss trials were higher than both clear loss and near-win trials. This is in contrast to past research using this procedure which has found that response rates, like response proportions, are a function of the number of red stimuli shown in the sample phase (Kyonka, Rice, \& Ward, in prep). Typically, near-win response rates are similar to those of wins and dissimilar to other loss trials types, which was not the case here.

To further analyze this potential difference, a repeated-measures ANOVA was conducted as described for response proportions. The analysis revealed a main effect of baseline condition, $F(3,12)=4.586, p=.023$, which indicated that response rates changed over the course of the experiment. The mean response rate was higher in the first baseline condition, $(M=10.08, S E=$ 2.33), than in the second $(M=7.81, S E=1.88)$, third $(M=7.61, S E=2.64)$, or fourth baseline conditions $(M=7.05, S E=1.88)$. The ANOVA also revealed a main effect of trial type, $F(3,12)$ $=12.57, p=.001$. However, the relation between response rates and a trial type's similarity to a win was not systematic. Pooled across baseline conditions, response rates were lowest for clear loss $(M=3.93, S E=1.17)$ and near-win $(M=3.66, S E=1.05)$ trials, higher for loss trials $(M=$ 
$8.46, S E=3.71)$, and highest for win trials $(M=16.50, S E=3.26)$. The large variability between in rates between sessions renders any potential differences between baseline conditions and trial types difficult to interpret.

In addition to response proportion and rate, the latency to peck the collect key can serve as a measure of response strength. For each session, median latency was calculated for each trial type. The median was used as the measure of central tendency instead of the mean because the median handles outliers and skewed distributions better than the mean, which are more common in latency data. Figure 5 shows means of the median latencies taken from the final five sessions of each baseline condition for each pigeon. Since omissions were rare for wins and most frequent for clear losses and losses, latencies for each trial type were calculated based on different sample sizes. Across pigeons, in 28 and nine sessions respectively, it was not possible to calculate latency for clear-loss or loss trials because the pigeon never pecked the collect key on that trial type.

Across all pigeons, the latency to peck the collect key appeared to decrease over time. However, a repeated-measures ANOVA using baseline condition and trial type as within-subject factors revealed no main effect of baseline condition $(p=.877)$ and no condition by trial type interaction $(p=.685)$. Only the main effect of trial type was statistically significant, $F(3,12)=$ $25.75, p<.001$. Latency to the first collect-key peck decreased as a function of the number of red stimuli shown in the sample phase increased. Clear losses had the longest latencies $(M=2.22$, $S E=0.25)$, followed by losses $(M=1.78, S E=0.29)$, near wins $(M=1.22, S E=0.21)$, and finally wins were the shortest $(M=1.03, S E=0.17)$. Bonferroni post-hoc analyses revealed that win and near-win latencies were significantly different from loss and clear-loss latencies. Taken together, this result demonstrates that win and near-win trials are similar in more than just 
response rate. The more similar a trial is to a win, the sooner a response is made on the collect key. Near-win latencies were also similar to win latencies while both were different than loss and clear-loss trials, indicating that near-win trials may function differently than other nonreinforced trials. In addition, there latencies did not change over the course of repeated baseline conditions.

Interresponse times (IRTs) during the sample phase were also analyzed using a repeatedmeasures ANOVA, using baseline condition, trial type, and key order as within-subject factors. IRTs from all baseline conditions were included in analyses. The ANOVA revealed significant main effects of trial type, $F(3,12)=42.71, p<.001$, and key order, $F(2,8)=26.58, p<.001$, and a significant interaction of trial type and key order, $F(6,24)=24.12, p<.001$. Taken together, these results indicated that IRTs were different for red and green keys and that the order of these keys mattered. Since clear-loss trials $(M=2.83, S E=0.24)$ were all green stimuli, IRTs for these trials were longer than win trials $(M=0.44, S E=0.05)$, which were all red stimuli. Loss $(M=1.95, S E=0.30)$ and near-win $(M=1.75, S E=0.24)$ IRTs were not significantly different from one another, but different from wins and clear losses. This decreasing trend illustrates the shift from long to short IRTs as a function of the number of reds shown in the sample phase. In addition to these findings, there was no significant effect of baseline condition $(p=.478)$, indicating that these IRTs did not change systematically across the experiment. IRTs for red stimuli were shorter than IRTs for green stimuli throughout the entire experiment.

For all extinction conditions, the number of trials completed were analyzed as a proportion of baseline trials. Figure 6 shows the number of trials completed in extinction as a proportion of baseline. A repeated-measures ANOVA was conducted using condition type (i.e., near-win present and near-win absent) and condition order (first or second extinction condition 
set) as within-subject factors and the number of sessions to extinction termination as the dependent variable. The analysis revealed no difference as a function of extinction type, $F(1,4)$ $=.043, p=.847$, which meant that the presence of near wins did not affect how long an extinction condition lasted. However, there was a main effect of condition order, $F(1,4)=7.92$, $p=.048$. This indicated that the later extinction conditions lasted longer than the earlier extinction conditions. In all but one case (Pigeon 301, near-win absent) the third and fourth extinction conditions lasted longer than the first two. In fact, the third and fourth extinction sessions lasted the maximum possible eight sessions in seven out of ten cases. By contrast, seven of ten first and second extinction conditions were terminated early after the number of trials completed dropped below the termination criterion. So, although loss-only and near-win extinction conditions were similar, later conditions lasted longer than earlier conditions.

\section{Discussion}

Pigeons experienced a three-stimulus sample phase where three red stimuli signaled a winning trial that ended in food contingent on a peck to a white collect key, which was presented on a separate key after the sample phase completed. There was an ordinal effect of the number of red stimuli shown in the sample phase on proportion of trials with a collect-key peck: more red stimuli shown in the sample phase led to higher probabilities of a response. That is, the more like a win a given trial was, the more likely a collect-key peck was. Collect-key response rates, calculated using trials where at least a single collect-key response occurred, did not follow the same pattern as response proportions. Instead, collect-key response rates were highest for wins and were not significantly different between any other loss trial types. However, mean response rates for the loss trials were higher than clear-loss and near-win trials. This is a different pattern than has been observed in past research (Kyonka, Rice, \& Ward, in prep). 
It was expected, based on previous research, that response rates would show the same pattern as response proportions. Given that the extinction conditions were the novel addition to this experiment, it may be that extinction conditions fundamentally altered how the pigeons responded on the collect key during baseline conditions. During extinction conditions, response proportion and rates typically increased for all trial types. It may be that this increase somehow influenced loss trials the most. As loss trials were the most common trial type across extinction conditions $(75 \%$ of trials in the near-win absent condition and $25 \%$ of trials in the near-win present condition), this may explain the discrepancy between the current experiment and past research. In order to elucidate this finding, further research needs to be arranged such that the probability of a trial type is manipulated and resulting changes in collect-key responding are captured. If the present results are an indication as to the potential effect, more experience with a trial type may increase collect-key responding. However, it may also be the case that experience with a trial type in extinction is required for this response rate increase to occur.

While several experiments have investigated the effects of near wins in extinction (e.g., MacLin et al., 2007; Peters et al., 2010), the current experiment is the first to do so while controlling for the number of stimuli shown in a session. Previous experiments have displayed loss trials with and without near wins, without accounting for the total number of winning stimuli displayed. Here, the number of red stimuli were equivalent in the near-win present and near-win absent extinction conditions. Interestingly, there was no difference in the number of trials completed across the two conditions. This may suggest that the mechanism by which near wins increase the time spent gambling in extinction (i.e., when wins are unavailable) in those procedures, was through conditioned reinforcement of specific winning stimuli displayed. Future research should replicate the current experiment without controlling the number of red 
stimuli shown across the two extinction conditions. That is, the near-win absent extinction condition should show clear losses and losses on half of the trials, thereby leading to a decrease in the total number of red stimuli shown in that condition. Should the number of red stimuli shown in a condition control responding, then it would be expected that the two extinction conditions would then show differences in the number of trials completed in extinction.

While there was no difference in trials completed in extinction based on the condition type (i.e., whether near wins were present or absent), there was a difference between first and second presentations of each extinction condition. Later extinction conditions lasted as long as or longer than the earlier extinction conditions. Response rates and the trials completed were expected to decline faster with repeated exposure to extinction conditions, as the pigeons would gain experience with periods without wins and responding would adapt more rapidly (i.e., decline quicker). However, that was not the case here. One possible reason this did not occur was the way conditions were ordered. Pigeons always experienced an extinction condition followed by a baseline condition. In this arrangement, continued responding during extinction was eventually met with the reintroduction of reinforcers. This could have reinforced continued pecking during the extinction condition and led to the longer extinction conditions in the second half of the experiment. One possible way to counteract this in future research is to run each extinction condition for much longer periods of time when doing multiple extinction conditions, such that any differences in the rate of decline would be more obvious and not subjected to the potential confound of reinforcing responding at the end of an extinction condition. This was not an issue in past extinction research (Côté et al., 2003; MacLin et al., 2007; Peters et al., 2010), because all of their extinction tests lasted for a single condition and were between-group 
comparisons. So, the merits of single-condition and multiple-condition extinction tests must be weighed when using these types of procedures.

In addition to the number of trials completed during extinction, collect-key response rates were also recorded. Responses that were previously unreinforced may become more common during extinction (e.g., Harris, Pental, \& LeSage, 2007). Here, response rates for loss trials increased to many times their baseline levels. Baseline collect-key response rates, however, were very low and often below 2 responses/min. Because the response rates were so low for loss trials during the baseline conditions, it makes it difficult to compare proportional changes in loss and near-win response rates. The disparity between near win and other losses was clear, however, which does provide additional support for the near-win effect.

Overall, the experiment revealed an important component of the near-win effect. Nearwin trials during extinction may serve as conditioned reinforcers and increase the time spent gambling, but the mechanism of that action is still relatively unknown. It is possible that nearwin trials themselves take on some conditioned reinforcing value or the individual stimuli can become reinforcers. The current experiment contradicts previous research using extinction tests and suggests that further research is necessary. Not only should the number of winning stimuli be varied across conditions, but multiple extinction conditions should be considered during experimental planning. Periods of extinction rarely occur in single bouts for human gamblers, so experimental arrangements can begin to arrange similar (but not identical) arrangements within the laboratory.

\section{Experiment 2}

One way to evaluate behavioral mechanisms involved in gambling is to present laboratory animal subjects with a choice between a small, certain reinforcer and a chance of 
receiving a larger reinforcer that is delivered with a probability $<1$. The expected value of each reinforcer is determined by the magnitude of the reinforcer when it is delivered and probability of reinforcement. As the probability of a reinforcer decreases, the expected value of that option also decreases. Gambling often involves choice between a certain, smaller reinforcer (e.g., working, social experiences) and a larger, probabilistic reinforcer (e.g., a jackpot). Choosing to gamble when the expected value of gambling is negative is an indication that the gambler's behavior is not sensitive to expected monetary value. The way different outcomes are signaled could promote or suppress gambling by altering sensitivity to overall expected value.

An experiment investigating choice of probabilistic reinforcers using pigeons has shown very clear gambling-like and suboptimal choice patterns (Laude et al., 2014). In these experiments, the initial link was composed of two different stimuli that each led to a different terminal-link schedule. These terminal links terminated with a smaller, certain reinforcer or a larger, probabilistic reinforcer. It was optimal for the pigeons to choose the initial-link stimulus correlated with the certain reinforcer, as it led to more food over the course of the entire session when both reinforcer magnitude and probability were taken into account. However, pigeons often chose the schedule associated with the larger, probabilistic reinforcer despite it being suboptimal to do so.

In Laude et al.'s (2014) experiment, pigeons were presented with a choice between certain and probabilistic outcomes and the choice was made with a single peck. In many concurrent-chain schedules with pigeons, different keys signal interdependently scheduled variable-interval (VI) initial links (e.g., Kyonka \& Grace, 2008). Each trial starts with a choice phase or initial link during which pigeons respond by pecking at either of two illuminated keys in an experimental chamber. Responses during the initial link produce one of two mutually- 
exclusive outcomes or terminal links, which end with food reinforcement after another schedule has been satisfied. The typical result is that pigeons respond more to the initial link preceding the terminal link associated with the relatively richer schedule of reinforcement (Grace \& Hucks, 2013). The matching law is a formal, quantitative description of this result, which, in its generalized form, states that response allocation in concurrent variable-interval schedules is a power function of relative reinforcer rate (Baum, 1974). The matching law is typically expressed in logarithmic form:

$$
\log \frac{B_{1}}{B_{2}}=a \log \frac{R_{1}}{R_{2}}+\log b,
$$

where $B$ is response rate, $R$ is reinforcer rate, and the subscripts 1 and 2 indicate the alternative schedules. Equation 1 has two parameters: bias, $\log b$, which is a constant preference for responding to either alternative that is independent of the reinforcer ratio, and an exponent, $a$, which is the sensitivity of response allocation to the reinforcer ratio. Baum (1979) showed that the generalized matching law provided an excellent quantitative description of choice in concurrent schedules, accounting for more than $90 \%$ of the variance in response allocation across a wide range of studies. Other reinforcer variables, such as magnitude or probability, can be included in the generalized matching law by concatenation of additional ratios (Baum \& Rachlin, 1969; Kyonka \& Grace, 2008).

A conditioned reinforcer is a stimulus that has acquired the ability to act as a reinforcer through a history of pairing with a biologically-relevant incentive such as food (Shahan, 2010; Williams, 1994a). Traditionally, the terminal-link stimuli in concurrent chains have been viewed as conditioned reinforcers and initial-link response allocation provides a measure of their relative effectiveness or value. According to this view, concurrent chains are concurrent schedules of 
conditioned reinforcement, as initial-link responding produces access to a stimulus associated with reinforcement (i.e., the terminal-link stimulus). This perspective has motivated the assumption that initial-link response allocation matches the relative rate of conditioned reinforcement (i.e., rates of terminal-link entry), and that relative terminal-link value combines multiplicatively:

$$
\frac{B_{1}}{B_{2}}=b\left(\frac{R_{1}}{R_{2}}\right)^{a_{R}}\left(\frac{V_{1}}{V_{2}}\right)^{a_{V}},
$$

where $R_{1}$ and $R_{2}$ correspond to rates of conditioned reinforcement, and $V_{1}$ and $V_{2}$ to terminal-link value. Equation 2 requires that in logarithmic terms, the effects on choice of relative conditioned reinforcement rate and value are additive and independent. Berg and Grace (2004) demonstrated this additive and independent property by placing pigeons into a concurrent-chains procedure where terminal-link entry was programmed at either $1: 2,1: 1$, or $2: 1$. That is, an initial link could lead to the entry twice as often as the alternative, the same amount as the alternative, or half as much as the alternative. Additionally, the immediacy of the reinforcer in the terminal link was manipulated across conditions. The immediacy is the reciprocal of the delay, meaning that higher immediacy indicates a reinforcer is delivered sooner in a terminal link. The authors demonstrated that initial-link response allocation was independently sensitive to both terminallink entry and immediacy. This finding demonstrates that the matching law is able to differentiate between multiple parameters of reinforcement, which allows for the independent evaluation of each.

Two parameters of reinforcement that can be used when fitting data with the matching law and are of particular interest in the current experiment are reinforcer probability and magnitude. Kyonka and Grace (2008) used a concurrent-chains procedure to manipulate 
reinforcer immediacy, magnitude, and probability in the terminal link. Initial-link response allocation was sensitive to all parameters. In addition, when all the parameters favored one terminal link (i.e., the terminal link delivered a larger reinforcer sooner and with a higher probability) that link was more preferred than when the parameters favoured both terminal links in some way. This indicated that each parameter individually contributes to initial-link response allocation, which is consistent with the predictions of the matching law.

In the current experiment, I evaluated choice between certain and probabilistic outcomes in a concurrent-chains schedule. White side keys signaled the initial links. Satisfaction of the initial-link schedule led to the middle link, which consisted of a sample phase that involved three red or green stimuli presented sequentially on the side key. A single peck was required to progress the three-stimulus sequence. Satisfaction of the middle-link schedule led to the terminal link, where the center key was illuminated white for $5 \mathrm{~s}$. A single peck was required during that time for food to be delivered on trials where it was scheduled (i.e., wins). Across conditions, reinforcer magnitude (number of hopper presentations) and probability were manipulated such that a side key led to more, equal, or less food in a session compared to the other alternative.

The schedules used in the current experiment were certain and probabilistic schedules. In the certain schedule, terminal links always terminated in food. In the probabilistic schedules, only $1 / 3$ of terminal links ended with food. There were two types of probabilistic schedules: with and without near-win trials. These three schedules (certain food, probabilistic food with no near wins, and probabilistic food with near wins) were compared in each possible pairwise arrangement.

In concurrent-chains procedures, initial-link response allocation is a measure of preference for one terminal link over another. This preference, specifically, the logarithm of the 
initial-link response ratio, is a measure of the terminal link's reinforcing value (e.g., Grace, 1994; Mazur, 2001). In the current experiment, I used a log-transformed version of the matching law (Equation 1) in order to determine preference for one schedule over another.

In this experiment, the rate of reinforcement delivered, $R$, was determined by reinforcer magnitude multiplied by the probability of reinforcement. When Equation 1 is applied to initiallink response allocation, the $a$ parameter estimates sensitivity to the relative expected food value of terminal links. If initial-link response allocation is sensitive to the probability or magnitude of reinforcement in each of the terminal links, then the sensitivity parameter should be greater than zero. Likewise, the bias parameter is a measure of any preference that is independent of the ratio of reinforcement. Given appropriate counterbalancing, a systematic bias will reveal any preference for the certain or probabilistic terminal link that is independent of the expected value. If near wins function as conditioned reinforcers, then the bias parameter for that schedule should increase over and above the bias already associated with (or against) the probabilistic schedule. That is, if near wins function as reinforcers, then initial-link response allocation for that schedule will increase.

By embedding gambling-like stimuli within a concurrent-chains procedure, the reinforcing effect of near wins can be determined when compared to probabilistic schedules without near wins and to alternatives when a small amount of food is delivered with certainty. This was accomplished by making pairwise comparisons between a schedule that always delivered reinforcement, a schedule that delivered reinforcement probabilistically without near wins, and a schedule that delivered reinforcement probabilistically with near wins. If the nearwin trial type has any reinforcing value then preference should develop for a schedule with near wins as opposed to a schedule without them. 


\section{Method}

\section{Subjects}

Three White Carneau pigeons (Columba livia) of mixed sex, numbered 303, 305, and 306, were housed and cared for as described in Experiment 1. These pigeons had experience with the previously described gambling task but not with concurrent-chains procedures, so all pigeons began in a concurrent-chains pretraining procedure.

\section{Apparatus}

The apparatus used was as described in Experiment 1.

\section{Procedure}

Pretraining. All pigeons began a concurrent schedule. Sessions lasted for 72 cycles or 70 minutes, whichever came first. At the start of each interval, the left and right keys were lighted white. Food delivery was interdependently scheduled, such that only one side key was active at any given time. The active side key was determined pseudorandomly with the constraint that in every block of 12 cycles, six were assigned to each key. A VI 8-s schedule was in effect on the active side key. The schedule for each side key contained 10 intervals sampled without replacement and was constructed from an exponential progression (Fleshler \& Hoffman, 1962). Once the initial-link interval timed out and a 1-s changeover delay was satisfied, a response to the active key produced food.

After three to five sessions when responses were recorded on both side keys, the concurrent schedule was changed to concurrent chains. Each cycle began with initial links that were identical to the concurrent VI 8-s schedule described in the previous paragraph. Satisfying the initial-link schedule produced fixed-interval (FI) terminal links. Terminal-link entry was signaled by darkening the side key that was not active and changing the color of the active key 
from white to red. Initially, left and right terminal links were identical FI 15-s schedules: the first peck to the active red key after $15 \mathrm{~s}$ had elapsed produced 3 -s access to food.

To confirm that response allocation was sensitive to changes in relative rate of reinforcement, terminal-link immediacy ratios were changed once a pigeon had completed all 72 cycles for at least two consecutive sessions and response allocation in the initial links was stable as determined by visual inspection. Terminal-link schedules were changed from FI 15-s schedules to FI $10 \mathrm{~s}$ on the left and FI $20 \mathrm{~s}$ on the right, or vice versa. In these arrangements, the programmed log terminal-link immediacy ratios were +0.30 and -0.30 when the FI 10 -s schedule was signaled by the left and right terminal link, respectively. A left-right pair of terminal-link schedules was maintained for a minimum of 5 sessions and until response allocation in the initial link favored the side key that produced the shorter terminal link schedule based on visual inspection of log response ratios. At that point, terminal-link schedules were switched and the new immediacy ratio was maintained until response allocation in the initial link shifted to favor the new shorter terminal link schedule. Pretraining ended after two alternations of the terminallink immediacy ratios.

Training. Following pretraining, all pigeons were placed into a five-link concurrentchains schedule. An example cycle is depicted in Figure 7. For reference, the first link will be referred to as the initial link. The second through fourth links will be referred to as the "sample phase" and the fifth link will be referred to as the "collect phase."

The initial link was the same interdependent VI 8-s schedule described in pretraining, except that the active side key was selected without replacement from a block of 30 with both side keys equally probable. The sample phase began as soon as the VI 8-s schedule timed out and the 1-s changeover delay was satisfied by a peck to the active initial-link key. Sample-phase 
entry was signaled by the darkening of the inactive side key. The active side key changed from white to either green or red, depending on the component and trial type. A three-link combination of red and green stimuli was displayed on the active side key during each sample phase with the restrictions that the key color could remain the same or change from red to green. Progression from second to third to fourth to fifth links each occurred with a single side key peck. That is, three pecks were required to progress through the entire three-link combination presented in the sample phase.

Red and green keys during the sample phase were winning and losing stimuli, respectively. Three red stimuli in a row signaled a "win," three green stimuli a "clear loss," and two red stimuli followed by a green a "near win." Figure 8 depicts the possible combinations of red and green stimuli and their associated trial-type labels. Trial type (i.e., win, near win, or clear loss) was determined by selecting without replacement from a list of 30 trials. The number of each type of trial included in the list varied depending on which components (described later) were assigned to left and right keys.

The collect phase began immediately after the third peck in the sample phase. Terminallink entry to the collect phase was signaled by darkening the side key and illuminating the center key. This "collect" key was illuminated white for $5 \mathrm{~s}$. On winning trials, the terminal link ended with food delivery if at least one peck occurred at any point during the 5-s presentation of the collect key. Pecks were recorded during near-win and clear-loss trials but they had no programmed consequence. Figure 7 illustrates the sequence of events that occurred during a win trial.

A 10-s intertrial interval separated each trial. On winning trials with collect-key pecks, the total duration of food delivery was subtracted from the intertrial interval so that time from the 
completion of the collect phase to the start of the next sample phase was held constant at $10 \mathrm{~s}$.

Sessions lasted 120 minutes, during which time subjects completed approximately 150-200 trials (303: $M=201.9, S D=19.0 ; 305: M=164.0, S D=42.0 ; 306: M=193.7, S D=26.2$ ).

Components. The frequency of wins, near wins, and clear losses differed across three different components. Table 3 shows the number of each type of trial in a block of 30 trials for each component. In the "Certain" component, wins were the only trial type that could occur. This made the Certain component a non-gambling option, as it always led to food. In the "Probabilistic" component, one third of the trials were wins and two thirds of the trials were clear losses. In the "Gambling" component, each trial type was programmed to occur equally often. For both the Probabilistic and Gambling components, food was only available in one third of the terminal links and therefore the component shared some properties with slot-machine gambling. The difference between the Probabilistic and Gambling components was whether or not near-wins were presented.

Pairwise Comparisons. The three different components were arranged in the three possible pairwise comparisons, Certain versus Probabilistic, Certain versus Gambling, and Probabilistic versus Gambling. The location of a component did not change within each comparison but could vary between comparisons. That is, if the Certain component was on the left key during the Certain vs. Probabilistic comparison, it was located on that key for all of that comparison, but could change position for the Certain vs. Gambling comparison. The location of components and order of conditions were partially counterbalanced across pigeons, as shown in Tables 4.1-4.3.

For each pairwise comparison, the relative rate of reinforcement for the two components was varied across three conditions to obtain estimates of bias and sensitivity using the 
generalized matching relation (Equation 1). The log reinforcer ratio is a logarithmically additive and independent combination of the probability and magnitude of a reinforcer calculated as:

$$
\log \left(\frac{R_{1}}{R_{2}}\right)=\log \left(\frac{P_{1} \cdot M_{1}}{P_{2} \cdot M_{2}}\right)
$$

Variables $P$ and $M$ are probability and magnitude (number of hopper presentations), respectively, and subscripts refer to the two side keys. For each pairwise comparison of components, pigeons were exposed to one condition when the left component was richer, one condition with equivalent rates of reinforcement, and one condition when the right component was richer. Because the probability of food was determined by the components scheduled on each side key, log reinforcer ratios were manipulated by changing the magnitude of reinforcement delivered following wins. The number of 3-s presentations of the food magazine ( $2.5 \mathrm{~s}$ of activation followed by a 0.5 -s deactivation) was manipulated across conditions. For each pairwise comparison, the $\log$ reinforcer ratios were $\log (3), \log (1)$ and $\log (1 / 3)$. That is, the schedule on the left key was richer, programmed rates of reinforcement were equivalent, and the schedule on the right key was richer, respectively. It was possible for a pigeon to earn 60 foodmagazine presentations per session in all conditions. Each condition lasted 14 sessions. Responding in initial links, sample phases and collect phases usually stabilized by the ninth session, as determined by visual inspection. Therefore, the last five sessions of each condition were used for all data analysis.

\section{Results}

\section{Initial-Link Response Allocation}

Responses in the initial link were aggregated in the final five sessions of each condition. Figure 9 shows log initial-link response ratios, plotted as a function of programmed log 
reinforcer ratio, for each pigeon in each condition. Each pairwise comparison consisted of three conditions in which the probability of food did not change, but the magnitude of food delivered on winning trials did. The label for each pairwise comparison lists the two components active at that time. For each column of panels in Figure 9, the first component listed was the numerator for response and reinforcer ratios, and the second component the denominator. For example, in the left column all initial-link response ratios were expressed as $\log \left(B_{\text {certain }} / B_{\text {probabilistic }}\right)$ and all programmed $\log$ reinforcer ratios as $\log (1 / 3), \log (1 / 1)$, and $\log (3 / 1)$. Of the 18 cases (six conditions $\times$ three pigeons) when one key was associated with a richer rate of reinforcement, initial-link response allocation favored the richer schedule in 13 of them.

The best-fitting line (Equation 1) was determined for each pairwise comparison to generate a linear function describing preference in the initial links. Here, preference is indicated by proportionally more responding to one alternative over another. Figure 9 shows the lines of best fit for all pigeons and each pairwise comparison. The slope of this line is the sensitivity parameter from Equation 1 and the y-intercept is the bias parameter. In eight of nine comparisons, the slope of the line is positive (Range: $0.34-1.26$ ). A positive slope indicates that initial-link response allocation was sensitive to the changes in reinforce magnitude across the three conditions. The slope in the Probabilistic vs. Gambling comparison was 0.02 for Pigeon 303, which indicates insensitivity to the changes in reinforcer magnitude and probability in this comparison. Across pigeons, the sensitivity parameters did not vary systematically between pairwise comparisons or change over time. There was no single comparison of components that engendered higher or lower sensitivity parameters than the others. In addition, there was no systematic ordinal effect across pigeons. 
The $y$-intercept, or bias parameter, is an estimate of preference for one alternative over another that is independent of the programmed log reinforcer ratio. Often, it represents a side key bias. As the different components were counterbalanced across keys, this bias parameter instead represents the different components. In this experiment the bias parameter is an estimate of tendency to choose one component over another, all else being equal. For example, in the Certain versus Probabilistic comparison, a positive bias indicates that response allocation favored a small amount of food every cycle. A negative bias indicates response allocation was risky: the pigeon preferred probabilistic over certain outcomes. The $95 \%$ confidence interval was calculated for all biases to determine which were significantly different from zero. Out of the nine bias parameters, eight were significantly different from zero. Table 5 shows each bias parameter and its associated $95 \%$ confidence interval in brackets.

For the bias parameter (i.e., y-axis intercept), systematic effects were observed in some comparisons. In the Certain vs. Probabilistic comparison, there was a bias towards the Certain component for Pigeon 303, no bias for Pigeon 305, and a bias towards the Probabilistic component for Pigeon 306. In the Probabilistic vs. Gambling comparison, Pigeon 303 preferred the probabilistic component, Pigeon 305 preferred the gambling component, and Pigeon 306 preferred the probabilistic component. In the Certain vs. Gambling comparison all pigeons preferred the Gambling component. In summary, there was a consistent preference for the Gambling component when the alternative was the Certain component, but no systematic bias in either the Certain vs. Probabilistic or Probabilistic vs. Gambling comparisons.

\section{Sample-Phase Interresponse Times}

Responding in the sample phase (i.e., middle links) was to three sequentially presented stimuli that appeared on a single key. In Experiment 1, IRTs for green keys were found to be 
longer than those of red keys. While that result was expected here, the component type might have also systematically affected IRTs. As such, repeated-measures ANOVAs using IRTs during the presentation of these stimuli were conducted to determine if there were systematic differences in how quickly pigeons pecked across conditions, comparisons, or key colors.

For ease of illustration, Figure 10 collapses data across the different conditions and depicts IRTs as a function of condition and pigeon. White bars indicate when the key color was green and black bars indicate when the key was red. IRTs for green keys were typically longer than those of red keys, the result found in Experiment 1. In addition, IRTs appeared similar across the different components. There was some intersubject variability in IRTs; Pigeons 303 and 305 typically had longer IRTs than Pigeon 306. As component type did not seem to affect IRTs, this indicated that the presence or absence of trial types within a session did not systematically alter IRTs of the available trial types. So, instead of the components that were present within a session affecting IRTs, it instead suggests that only the currently active trial or possibly recent trials control behavior.

To further investigate IRTs obtained within the sample phase, separate repeated-measures ANOVAs were conducted for each of the three trial types. Separate analyses were conducted because some trial types were not present in some conditions and pairwise comparisons (e.g., the Certain component did not have near wins or clear losses to enter into the ANOVA).

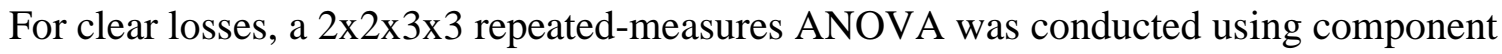
type (Probabilistic and Gambling), pairwise comparison, reinforcer ratio (1:3, 1:1, and 3:1), and key order (first, second, or third key in the FR 3) as factors. There was no difference across component types $(p=.663)$, pairwise comparisons $(p=.852)$, or key order $(p=.336)$. There was a significant main effect of condition, $F(2,4)=13.736, p=.016$. Overall IRTs on clear loss trials 
were highest when the reinforcer ratio was equal across components $(M=1.96, S E=0.50)$, followed by when the Probabilistic component was richer $(M=1.648, S E=0.42)$, then when the Gambling component was richer $(M=1.465, S E=0.41)$.

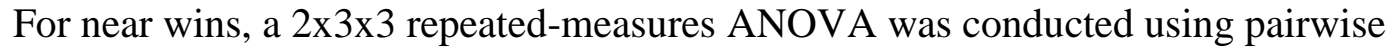
comparison, reinforcer ratio, and key order as factors, as described above. Component type was not included as a factor, as there was only a single component where near wins were present: the Gambling component. IRTs did not vary as a function of pairwise comparison $(p=.660)$, reinforcer ratio $(p=.994)$, or key order $(p=.101)$.

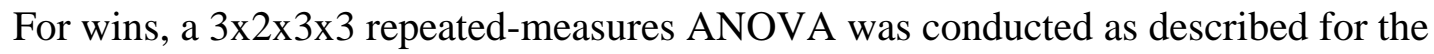
clear losses, with the only difference being an additional component (the Certain component) being included in the analysis. There was no difference in IRTs as a function of component type $(p=.431)$, pairwise comparison $(p=.075)$, reinforcer ratio $(p=.437)$, or key order $(p=.056)$. However, there was a significant component $\mathrm{x}$ key order interaction, $F(4,8)=3.972, p=.046$. Further analysis of this interaction revealed that when the reinforcer ratio was equal across components the IRTs were more similar across the three-stimulus sequence than in the conditions where the reinforcer ratio was unequal (i.e., one component was richer). While statistically significant, it is difficult to determine the application of the finding. It may indicate that IRTs vary as a function of reinforcer ratio, but only for certain keys. Further studies would be required to parse this interaction.

\section{Collect-Phase Responding}

The collect key was presented for $5 \mathrm{~s}$ after the sample phase and required at least one peck to occur during that time for food to be accessible following a win. To characterize responding on the collect key, the proportion of trials where a peck occurred and the rate of 
responding on the collect key were calculated. Response rates were calculated such that only trials where at least one peck occurred were entered into the analysis. Table 6 displays the average number of omission trials for each near-win probability as a function of component and trial type.

Response proportions and rates, collapsed into component type, are depicted in Figure 11. For response proportions, there is minimal between-subject variability and all proportions are similar across the different components. In addition, proportions are ordinally identical across pigeons. Pecks occur on almost all win trials (Range: .958 - .999) and occur rarely on clear loss trials (Range: .015 - .127). Near wins response proportions are higher than clear losses and lower than wins and are the most variable between subjects (Range: $.250-.523$ ). The more reds shown during the sample phase, the more likely a response was during the collect phase. That is, the more similar to a win a trial was, the more likely the pigeon was to peck the collect key to collect food.

Response rates were more variable between pigeons than response proportion but were also similar across components. While there were individual differences in response rates, the ordinal effects were once again identical across pigeons. Response rates on clear loss trials were the lowest (Range: $2.04-7.11$ pecks/collect phase) and were highest during win trials (Range: $7.22-20.78$ pecks/collect phase). Near wins were similar to win response rates (Range: $7.12-$ 18.01 pecks/collect phase) and were higher than clear loss rates. So, while near wins and wins differed in the proportion of trials where a peck occurs, when pecking did occur it was at an equivalent rate. This indicates that the probability that a collect-key peck occurs and the resulting response rate may be two processes that can be affected independently. 
To investigate these ordinal effects, repeated-measures ANOVAs were conducted for each trial type using response proportion and response rate as outcome variables. These ANOVAs were arranged in the same manner as described for IRTs. Neither response proportion or response rates varied as a function of component type, pairwise comparison, or condition $(p$ value range: .056 - .931). This demonstrated that the components in effect did not alter response proportion or response rates. Instead, only the stimuli that were shown during the sample phase controlled responding to the collect key. The more reds shown in the sample phase, meaning the more similar to a win it was, the more likely a peck occurred and response rates also increased.

In addition to response proportions and rates, the median latency to the first peck on the collect key was calculated using only trials where a peck occurred. Latencies tend to have a nonnormal distribution that has positive skew, and as such the median is a more appropriate measure for IRTs. Mean latency measures are more prone to be influenced by outliers, which are common in latency measures. Latencies from the last five sessions were averaged for each condition. Figure 12 shows the latencies for each component as a function of trial type. For Pigeons 303 and 306, there were no systematic differences in latencies across component type or trial type - all latencies were similar. For Pigeon 305, clear loss latencies were higher than nearwin and win latencies. For this pigeon, the latencies for near wins and wins were similar.

To further investigate these visual trends, repeated-measures ANOVAs were conducted as described for response proportions and response rates. Latency did not differ as a function of component type, pairwise comparison, or condition for any of the trial types ( $p$-value range: .076 - .973). This finding confirmed the visual analysis, in that latencies did not differ across the components when collapsed across subjects. However, there was a significant component type $\mathrm{x}$ condition interaction for clear losses, $F(2,4)=7.722, p=.042$. Latencies in the Gambling 
component (Range: $1.83-2.60 \mathrm{~s}$ ) were lower than the Probabilistic component (Range: 2.33 2.60 s) except in the 1:1 condition (i.e., when the two components delivered equal amounts of food).

There was also a significant pairwise comparison $\mathrm{x}$ condition interaction for near-win collect-key latencies, $F(2,4)=8.082, p=.039$. Near-win latencies were lower in the Probabilistic vs. Gambling comparison (Range: $1.03-1.22$ s) than the Certain vs. Gambling comparison (Range: $1.51-2.33 \mathrm{~s}$ ). The interaction was significant because while the latencies were stable across conditions in the Probabilistic vs. Gambling comparison, latencies in the Certain vs. Gambling comparison were similar in the 1:3 and 1:1 condition but not the 3:1 condition (i.e., when the Certain component was richer).

\section{Discussion}

The gambling task used in this experiment was successfully embedded within a concurrent-chains procedure. By doing so, measures of initial-link response allocation, samplephase IRTs, and collect-key response proportion, rates, and latencies were obtained. Responding in this arrangement showed preference for the Gambling component over the Certain component, faster IRTs for red keys over green keys in the sample phase, and the near-win effect for collectkey response proportions and rates. The critical pairwise comparisons within this experiment were the Probabilistic and Gambling components compared the Certain component. These comparison were equivalent in most ways, in that both the Probabilistic and Gambling delivered probabilistic reinforcement (1/3 of the trials) and were compared to a non-gambling alternative. In these comparisons, the only difference was the presence of near-win trials in the Gambling component. When the near-win trials were not present, there was no preference for the Probabilistic component. However, when near-win trials were added, preference clearly shifted 
to the Gambling component. This is definitive evidence that the presence of near-win trials can affect preference among gambling and non-gambling alternatives.

To date, there have been few attempts to understand choice between gambling options. Dixon, Maclin, and Daugherty (2006) allowed human participants to allocate responses to two slot machine: one which paid out frequently (one in every 10 trials) in small amounts and one which paid out infrequently (one in every 50 trials) with large amounts. The payout amounts were arranged such that both alternatives delivered the same payout over the course of an entire session. Despite this equality, participants preferred the slot machine with more frequent payouts. However, this experiment only manipulated reinforcer magnitude and probability and no attempt was made to alter the probability of a near-win trial, so little can be said about the effect near wins have on preference.

In a follow up study, Maclin and colleagues (2007) gave human participants experience with three slot machines with varying probabilities of near-win trials: $15 \%, 30 \%$, and $45 \%$. The amount of programmed reinforcement among the alternatives was otherwise equal. The participants were then placed into an extinction condition where wins (and therefore reinforcement) were removed. Participants could then choose to play any of the three slot machines. While it appeared that higher near-win probabilities encouraged more gambling in extinction, there was no significant difference in response allocation across all of the subjects. The authors went on to divide the participants up into a group that played under 100 trials in extinction and a group that played over 100 trials in extinction. The group that played under 100 trials showed no preference in their choice of slot machine. The group that played over 100 trials, however, showed a clear preference for higher near-win probabilities. The authors did not present any individual data or standard deviations, so it is difficult to determine to what extent 
individual response patterns varied in this task. Despite these potential shortcomings, it suggests that near-win probability may affect choice between gambling options.

The current experiment successfully extended previous findings using an animal model and demonstrated the choice of gambling over non-gambling alternatives can be obtained in certain situations. However, there was no clear preference for the Probabilistic over the Certain component, as was expected given past research using pigeons (Laude et al., 2014). One potential explanation for this discrepancy is the duration of the conditions used within the current experiment.

Conditions were limited to 14 sessions due to practical and logistical issues. In some cases, responding within a condition had not yet stabilized when that condition was terminated. These instances typically occurred after a large change between conditions (e.g., going from 1:3 to $3: 1$ reinforcer ratio). It is likely that the relative complexity of the task used in the current experiment lengthened the time needed for responding to stabilize. It is possible that this increased time requirement paired with the brief 14-session conditions prohibited the development of a bias for the Probabilistic over the Certain component. The largest predicted bias was the Gambling over Certain component, which was found here. It may be the case that limiting the condition length decreased the power of the experiment, thereby only revealing the largest predicted difference. In order to determine this, replications using longer conditions and more flexible stability criteria are recommended.

The current experiment also revealed difference in IRTs during the sample phase. Other experiments studying gambling in animals (e.g., Peters et. al., 2010, Winstanley, Cocker, \& Rogers, 2011) were arranged in such a way that stimuli were presented following a single response. The use of multiple responses within the sample phase in the current experiment 
allows for additional data to be collected. These data revealed that IRTs following the presentation of a red stimulus were shorter than IRTs following a green stimulus. Red stimuli were paired with food reinforcement following a win, which may have led to the red stimulus taking on conditioned reinforcing properties. That is, due to the frequent pairing with food, red stimuli became reinforcers. This is similar to the idea that near wins become reinforcers for human gamblers.

For human gamblers, any matching stimuli signal a win and therefore a single stimulus does not necessarily become a reinforcer. Instead, human gamblers see arrangements of stimuli which are more or less correlated with reinforcement. Wins are followed by reinforcement and become reinforcing, which may generalize to near wins. In the current experiment, the near win is always two red stimuli followed by a green stimulus and a win is always three red stimuli. Because of this, both near-win trial types and red stimuli may become conditioned reinforcers. That is, near wins may become conditioned reinforcers through the process hypothesized for human gamblers. In addition, since red stimuli are always correlated with food and green stimuli are not, which is unlike the human slot-machine play, the red stimulus may also become a condition reinforcer.

Having red stimuli and near-win trials as conditioned reinforcers help explain the observed bias for the Gambling over Certain component. If it was simply the probabilistic food that determined preference, then the same bias should have been observed in the Probabilistic over the Certain component. However, that was not the case. Instead, the bias for the Gambling component was higher, indicating that the near win trials may have acted as conditioned reinforcers and influenced initial-link response allocation. Despite this possibility, the Gambling component was not preferred over the Probabilistic component. If near wins were functioning as 
conditioned reinforcers, the Gambling component should have been preferred. Given the relatively brief conditions and the similarity between the Gambling and Probabilistic components, more research with longer conditions will be needed comparing these two schedules to help elucidate the role near wins play in determining preference. Experiment 3 attempts to address some of this issue by comparing the Certain component to the Gambling component where the probability of a near-win trial is varied.

In addition to generating sample-phase IRTs, the current procedure also generates three separate measures of collect-key responding: proportion, rate, and latency. These measures have been analyzed outside of the concurrent-chains procedure (Kyonka et al., in prep). The results found here are in line with previous research - collect-key response proportion and rates were a function of the number of red stimuli shown in the sample phase. This was not the case for latencies, however, which were not systematically affected by sample-phase stimuli across subjects. The more similar to a win a trial is, the more likely a collect-key response is and the higher the subsequent response rate. Why latencies are not influenced by sample-phase stimuli is currently unknown, but it may suggest that separate processes govern these two distinct patterns of behavior.

Collect-key response proportion and rates are similar to past research investigating the near-win effect. Human gamblers reported that near wins were more similar to wins and losses (Dixon \& Schreiber, 2004). Analysis of skin conductance in human gamblers also showed that the reaction following a near win was similar to that of a win (Clark et al., 2012; Dixon et al., 2013). In addition, rats responding in a gambling task started a new trial more rapidly after a loss than a win. Near win latencies to initiate a trial were more similar to a win than a loss (Peters et al., 2010). In all of these cases, these measures show that near wins were more similar 
to wins than losses. These findings are in line with the current results in that response proportions and response rates were similar between near wins and wins.

Taken together, the results obtained in the current experiment demonstrate the utility of this procedure. Not only was the near-win effect observed in collect-key response proportions and response rates, but additional measures of responding were collected that are not obtained in other procedures. IRTs for red and green stimuli showed distinct patterns which may suggest excitatory/reinforcing and inhibitory/punishing effects, respectively. In addition, this procedure is the only experiment to successfully embed a slot-machine analog into a concurrent-chains procedure. By doing so, measures of preference were obtained between gambling and nongambling alternatives. This procedure also allows for the systematic manipulation of reinforcer magnitude, probabilities of each trial type, the number and type of stimuli used in the sample phase, and changing the contingencies of the collect key. These possible manipulations allow for an extensive investigation into the discriminative and reinforcing properties of gambling-like stimuli, which is an area that is still not well understood and warrants more research.

\section{Experiment 3}

Experiment 2 demonstrated that preference for the Gambling component was a function of the near-win trials. Since the only difference between the Probabilistic and Gambling components was the presence of near wins, any difference in preference can be attributed to the near-win trials. The Probabilistic component was not preferred over the Certain component while the Gambling component was. As such, the near-win trials directly led to the preference for the Gambling component over the Certain component. Despite this finding, it is still unknown if the probability of a near-win trial can systematically affect preference. Experiment 2 used only two near-win probabilities: 0\% (Probabilistic) and 33\% (Gambling). 
To date, only one study has been conducted to determine if near-win probability affects preference between gambling options. Maclin et al. (2007) had college undergraduates play three virtual slot machines for points. The payout was the same on all three slot machines, but each slot machine was programmed with a different frequency of near-win trials. Near wins were $15 \%, 30 \%$, or $45 \%$ of all trials. Participants were allowed to allocate their playing time to any of the three available machines. There were no significant differences in the allocation of play during extinction between the three machines. The authors went on to divide the participants up into two groups: those that played under 100 trials in extinction and those that played over 100 trials. There was no difference in which machines were played by the participants that played under 100 trials. However, for the group that played over 100 trials in extinction, there was more play allocated to the $30 \%$ and $45 \%$ machines. These results indicate that sensitivity to near wins varies between individuals, but provides some evidence for the role near-win trials play in choosing to gamble and preference between gambling options.

Near wins have not been investigated in a concurrent-chains procedure to determine how their presence affects preference. The purpose of Experiment 2 was to investigate how probabilistic and near-win components can affect preference when compared to each other and to a non-gambling task. However, the relative frequency of near-win presentations was held constant in Experiment 2 at either $0 \%$ or $33 \%$. If near wins affect preference, either through conditioned reinforcement or stimulus generalization, changes in the relative frequency of near wins should be matched by changes in initial-link response allocation. Experiment 3 sought to investigate this prediction by systematically altering the relative frequency of near-win trials in the Gambling component described in Experiment 2. The alternative schedule in effect was the Certain component (i.e., a non-gambling alternative). 


\section{Method}

\section{Subjects and Apparatus}

The subjects and apparatus used were as described in Experiment 2.

\section{Procedure}

The same concurrent-chains procedure from Experiment 2 was used in the current experiment. However, in all phases and pairwise comparisons of this experiment, the two available components were always the Certain and Gambling components. The relative rate of reinforcement between these two components was manipulated across conditions. The two relative-reinforcement ratios used in the current experiment were 1:3 and 3:1 and the number of reinforcers per win for each ratio (i.e., magazine presentations) was the same as those described in Experiment 2 (e.g., conditions 7 and 9 in Table 4.1).

There were four phases in this experiment, which were named according to the probability of a near-win trial in the Gambling component: $0 \%, 7 \%, 17 \%$, and $33 \%$. The data for the $0 \%$ and $33 \%$ phases were obtained from the Probabilistic and Gambling components in Experiment 2, respectively. The data for the $7 \%$ and $17 \%$ phases were collected in the current experiment. Each condition (i.e., each relative-reinforcement ratio - 1:3 and 3:1) lasted 14 sessions and the order of conditions was partially counterbalanced across pigeons, as shown in Table 7.

\section{Results}

\section{Initial-Link Response Allocation}

As in Experiment 2, initial-link responses were aggregated across the final five sessions in each condition. Figure 13 displays the log-response ratios and lines of best fit for each pigeon in each condition, plotted as a function of programmed log reinforcer ratio. Unlike Experiment 
2, only two components were used: Certain and Gambling. In addition, only two reinforcer ratios were used in each pairwise comparison. As such, each panel consists of two data points; the leftmost data point represents the $\log (1 / 3)$ reinforcer ratio (i.e., the Gambling component was richer) and the rightmost data point represents the $\log (3 / 1)$ reinforcer ratio (i.e., the Certain component was richer). Of the 24 cases (eight conditions $\times$ three pigeons) when one key was associated with a richer rate of reinforcement, initial-link response allocation favored that key in 18 cases.

The best-fitting line (Equation 1) was determined for each pairwise comparison to generate a linear function that described preference in the initial links. The slope of this line is the sensitivity parameter from Equation 1 and indicates how initial-link response allocation changed as a function of reinforcer magnitude within a condition. In all twelve comparisons, the slope of the best-fitting line was positive (Range: $0.34-1.38$ ). Across pigeons, the sensitivity parameter did not systematically vary between conditions.

The $y$-intercept, or bias parameter, is an estimate of preference for one alternative over another that is independent of the programmed log reinforcer ratio. As in Experiment 2, the bias parameter is an estimate of tendency to choose one component over another, all else being equal. The $95 \%$ confidence interval was calculated for all biases to determine which were significantly different from zero - all twelve bias parameters were significantly different from zero. Table 8 shows each bias parameter and the associated confidence intervals.

To better illustrate the change in preference as a function of near-win probability, Figure 14 replots the bias parameters for each condition across pigeons. Bias parameters that are positive indicate a preference for the Certain component and negative bias parameters indicate a preference for the Gambling component. For the $0 \%$ condition, Pigeons 303 and 305 preferred 
the Certain component and Pigeon 306 preferred the Gambling component. For the 7\% condition, Pigeon 303 preferred the Certain component, while Pigeons 305 and 306 preferred the Gambling component. This was also the case in the $17 \%$ condition - Pigeon 303 preferred the Certain component and Pigeons 305 and 306 preferred the Gambling component. In the 33\% condition, all pigeons preferred the Gambling component.

Taken together, the frequency of a near-win trial increased preference for that alternative. However, it is important to note the different patterns exhibited by the three pigeons. Pigeon 303 showed a graded effect, where preference shifting from the Certain component to the Gambling component as near-win probability increased. For Pigeon 305, it was simply the presence or absence of near-win trials that controlled preference for the Gambling component. Lastly, Pigeon 306 was sensitive to the probabilistic reinforcement in the Gambling component; since there was already a preference for the Gambling component, near-win trials had no further effect. The different patterns shown here may suggest large individual variability in the sensitivity to near-win trials.

While patterns in preference differed between subjects, more pigeons preferred the Gambling component when that component had higher near-win probabilities. Across conditions, mean bias for the Gambling component decreased monotonically from 0.01 in the $0 \%$ condition, when near-win trials were absent, to -0.46 in the $33 \%$ condition, when a third of all trials were near wins. The more near-win trials there were in a session, the more the Gambling component was preferred.

\section{Sample-Phase Interresponse Times}

Responses in the sample phase were to three sequentially-presented stimuli that appeared on a single key. As in Experiment 2, repeated-measures ANOVAs were conducted for each trial 
type using IRTs as the outcome variable and near-win probability and key order as withinsubject factors. As there were only two components active in this experiment (Certain and Gambling), component was only a factor in the analysis of win IRTs. Since the Certain component did not have any other trial type other than wins, there could be no comparisons across components for clear-loss and near-win IRTs. Median IRTs were calculated from the last five sessions in each condition.

Figure 15 shows the mean IRTs for each pigeon and each condition. Clear losses, near wins, and wins each have their own series within a panel. Longer IRTs indicate more time elapsing between each consecutive response to the three-stimulus sequence. White bars indicate when the key was green and black bars show when the key was red during that link of the sample phase. Across pigeons, the patterns of IRTs were similar to those seen in Experiment 2. IRTs for red keys were typically shorter than IRTs for green keys. There also did not appear to be any difference across the different components - that is, the pattern of responding was similar regardless if it was the Certain or Gambling component. To further investigate these trends, repeated-measures ANOVAs were conducted for each of the trial types.

For sample-phase IRTs in clear-loss trials, a 4x2x3 repeated-measures ANOVA was conducted using near-win probability $(0 \%, 7 \%, 17 \%, 33 \%)$, reinforcer ratio (1:3 and 3:1), and key order as factors. There was no significant difference as a function of near-win probability ( $p$ $=.805)$ or key order $(p=.427)$ or any interactions ( $p$-value range: $.609-.878)$. However, there was a significant difference as a function of reinforcer ratio, $F(1,2)=30.794, p=.031$. IRTs in clear loss trials were longer in the $3: 1$ condition $(M=1.36, S E=0.19)$, when the Certain component was richer, than in the $1: 3$ condition $(M=1.07, S E=0.23)$, when the Gambling component was richer. 
For sample-phase IRTs in near-win trials, a 4x2x3 repeated-measures ANOVA was conducted as described for clear loss trials. There was no significant difference in IRTs as a function of near-win probability $(p=.392)$, reinforcer ratio $(p=.321)$, or key order $(p=.249)$. All interactions were also nonsignificant ( $p$-value range: .347 - .738).

For sample-phase IRTs in win trials, a $2 \times 4 \times 2 \times 3$ repeated-measures ANOVA was conducted using component (Certain and Gambling), near-win probability (0\%, 7\%, 17\%, 33\%), reinforcer ratio (1:3 and 3:1), and key order as factors. There was no significant difference in IRTs as a function of component $(p=.396)$, near-win probability $(p=.573)$, reinforcer ratio $(p=$ $.142)$, key order $(p=.058)$, or any of their interactions ( $p$-value range: .053 - .992).

\section{Collect-Phase Responding}

The collect key was presented for $5 \mathrm{~s}$ following the termination of the sample phase and required at least one peck during that time for food to be accessible following a win. Table 9 displays the mean number of omission trials in each condition for wins from the Certain component and separately for each trial type from the Gambling component. To determine how collect-key responding might have changed as a function of component, near-win probability, and reinforcer ratio, the proportion of trials where a peck occurred and the rate of responding on the collect key were calculated. Response rates were calculated using trials where at least one peck occurred to the collect key. As such, response rates for clear-loss, near-win, and win trials had different denominators for response rate calculations.

Figure 16 depicts the response proportions (left column) and response rates (right column). These data are collapsed into component type for ease of illustration. For response proportions, there was minimal between-subject variability and proportions for win trials were similar across the Certain and Gambling components. Within the Gambling component, 
proportions typically increased as a function of the number of red stimuli shown in the sample phase. Pecks occurred on almost all win trials (Range: .768 - 1.0) and occurred less frequently on clear-loss trials (Range: 0.0 - .307). Proportions during near-win trials were intermediate to both wins and clear losses (Range: .036 - .867) and were more variable between subjects. The more similar to a win a trial was, the more likely a peck was during the collect phase.

Response rates showed more between-subject variability than response proportions. Collect-key response rates during win trials were also similar between the Certain and Gambling components. Like response proportions, response rates increased as a function of the number of reds shown in the sample phase. Response rates were highest during win trials (Range: 5.43 20.59 pecks/collect phase) and lowest during clear-loss trials (Range: $0.0-10.4$ pecks/collect phase). Near-win collect-key response rates were intermediate to wins and clear losses (Range: $3.9-16.8$ pecks/collect phase). As was the case with response proportions, the more similar a trial was to a win, the higher the collect-key response rate.

To further investigate these trends, repeated-measures ANOVAs were conducted for each trial type using response proportion and response rate as outcome variables. These ANOVA were arranged as described for IRTs. Across all the different trial types, response proportions and response rates did not vary as a function of component type (Certain and Gambling), nearwin probability $(0 \%, 7 \%, 17 \%, 33 \%)$, or reinforcer ratio $(1: 3$ and $3: 1)$ ( $p$-value range: .058 .949). This indicated that collect-key responding did not differ between the Certain and Gambling components. In addition, reinforcer ratio and near-win probability did not systematically alter collect-key responding. While session-wide variables did not alter collectkey responding, the stimuli shown in each trial were important. The more red stimuli shown in 
the sample phase, the more likely a peck was to occur during the collect phase. In addition, when a peck did occur, response rates were higher for trials that were more similar to a win.

As in Experiment 2, median latency to the first collect-key peck was calculated using only trials where a peck occurred. Latencies for the last five sessions were averaged for each reinforcer ratio. Figure 17 shows the latencies for each pigeon and trial type. Data were collapsed into component type for ease of illustration. As was in Experiment 2, there were no differences in latencies as a function of trial type for Pigeons 303 and 306. That is, the time to the first collect-key peck occurred at approximately the same time regardless of trial type for these pigeons. For Pigeon 305, latencies decreased as a function of the number of red stimuli shown in the sample phase. The more red stimuli displayed, the less time it took for the first collect-key peck.

Repeated-measures ANOVAs were conducted for each trial type to further investigate these potential differences. Latencies were used as the outcome variable and component type (Certain and Gambling), near-win probability $(0 \%, 7 \%, 17 \%, 33 \%)$, and reinforcer ratio $(1: 3$ and 3:1) were used a within-subject factors. Across all the different trial types, there were no differences in latencies as a function of component type, near-win probability, or reinforcer ratio ( $p$-value range: .085 - .948). These results once again indicate that session-wide variables, such as near-win probability and reinforcer ratio, did not affect the time to the first collect-key peck. While the number of red stimuli shown in sample phase affected collect-key response proportions and rates, it did not seem to have a systematic effect on collect-key latencies. Only Pigeon 305 showed a difference in latency across the different trial types. 


\section{Discussion}

In general, the results from the intermediate near-win probabilities of Experiment 3 were similar to those obtained in the Probabilistic and Gambling components in Experiment 2. Collect-key response proportion and response rate were influenced by the number of red stimuli shown in a trial and not by session-wide variables, such as reinforcer ratio or near-win probability. IRTs during the sample phase showed shorter latencies for red stimuli compared to green stimuli. In addition, the initial-link response ratios extended the results found in Experiment 2 by using near-win probabilities between the $0 \%$ and $33 \%$ in the Gambling component. Experiment 2 revealed that near-win trials can affect preference and the current experiment demonstrated that near-win probability systematically alters preference; the more near-win trials in a session, the greater the bias was for the Gambling component.

The additional near-win probabilities used in the current experiment revealed intersubject variation in sensitivity of response allocation to different parameters of the experiment. Pigeon 306's initial-link response allocation showed a clear bias towards the Gambling component, regardless of the near-win probability. This suggests that this pigeon was more sensitive to the probabilistic nature of the reinforcer and it was difficult to determine any changes in preference due to near-win probability. That is, since responding already heavily favored the Gambling component, near-win probability could not exert any additional control over preference. Initiallink response allocation for Pigeon 305 showed a bias for the Certain component when the nearwin probability was $0 \%$ and then preference for the Gambling component when it was $7 \%, 17 \%$, and $33 \%$. For this pigeon, the presence of near-win trials was enough to influence preference and the probability of the near-win trial appeared less important. It is possible that there is a near-win probability less than $7 \%$ which could produce a bias parameter that is intermediate to 
the $0 \%$ and $7 \%$ probabilities. However, the sensitivity of the pigeon to near-win trials would make that determination difficult. The bias parameters for Pigeon 303 changed gradually as the near-win probability increased. That is, the more near wins presented in a session, the higher the preference for that component.

In spite of intersubject variation in initial-link response allocation, the systematic relation between bias and the frequency of near wins makes it clear that near-win trials affect preference. The degree to which these trials affect preference does seem to vary between subjects and might be highly variable within a population. This is of particular interest, as near wins might be a contributing factor for problem gambling. If problem gamblers have a particular sensitivity to near-win trials, that provides as least some explanation and potential ways to address the disorder. In addition, while preference did vary as a function of near-win probability, samplephase IRTs and all collect-phase responding were insensitive to these manipulations. This suggests that separate processes govern the choice of gambling alternatives and the behavior that occurs when engaged with the alternative. How this knowledge can be applied is lacking, but it suggests that targeting the choices gamblers may make instead of how they gamble may be an important distinction to consider.

\section{General Discussion}

Gambling is a complex behavior that requires more research to be fully understood. The results discussed here add to this growing body of literature in unique and meaningful ways. Much of the gambling research conducted this far has focused on near-win trials and their effect on gambling persistence in extinction. However, Experiment 1 showed that near-win trials alone might not be sufficient to produce this effect. It might also be the case that other reinforcercorrelated stimuli (i.e., red keys) may also produce this effect. This would explain why the 
results from Experiment 1 contradict other studies. If red stimuli became conditioned reinforcers like a near-win trial, then no effect would be observed, as was reported here.

In addition, Experiments 2 and 3 were the first time a gambling schedule has been embedded into a concurrent-chains procedure. By doing so, measures of initial-link response allocation were obtained which clearly demonstrated the effect near-win trials have on gambling preference. Probabilistic schedules were not favored over certain food, but the addition of nearwin trials changed preference to favor the probabilistic/gambling schedule. This clear and marked difference serves as evidence for the control near wins have over choice. Experiment 3 sought to examine this further by systematically manipulating the probability of a near-win trial. Interestingly, higher near-win probabilities led to a larger bias for the gambling schedule. In other words, the more near-win trials shown in a session, the more attractive the gambling options became. The animal model presented here extends the literature by uniquely controlling possible conditioned reinforcement in extinction, presenting a within-subject approach to gambling in extinction, implementing a concurrent-chains procedure to test for potential gambling preferences, and determining how preference is affected by reinforcer magnitude, reinforcer probability, and near-win probability.

Animal models of gambling offer unique opportunities to study basic processes, such as stimulus control and conditioned reinforcement, which govern gambling behavior in humans. These animal models have successfully replicated the near-win effect and also provide additional benefits, such as greater experimental control and longer experimental times, which lead to more data collection and make a within-subject approach more feasible. The work done by Peters et. al (2010) and Laude et al. (2014) have laid the ground work for more complex experimental arrangements, such as those used here in Experiments 2 and 3. Further research using animal 
models will be able to create better analogues of human gambling and will be more likely to generate results that can directly lead to treatments or interventions.

The pigeons used in this experiment preferred a gambling-like schedule over certain food, which is a pattern of behavior exhibited by problem gamblers. With additional research, the mechanism that controls this choice will be better understood. As of now, near-win trials clearly affect preference, though additional research is necessary. The current experiment, and other animal models, often present near wins as a single arrangement of stimuli. Here, near wins were always two red stimuli followed by a green stimulus. This arrangement can be modified to be more similar to slot-machine play in a variety of ways. For example, near wins can be redgreen-red or green-red-red stimulus combinations. Additional stimuli can also be added, such that any single stimulus does not signal winning and losing, but instead must be matched with other stimuli as would be the case for human gamblers. By doing so, the animal models used to study gambling will continue to improve and the complex role near wins play in controlling slotmachine play will be better understood. 


\section{References}

American Gaming Association (2013a). Gaming Revenue: 10-Year Trend. Retrieved from http://www.americangaming.org/industry-resources/research/fact-sheets/gaming-revenue10-year-trends.

American Gaming Association (2013b). State of the States: The AGA Survey of Casino Entertainment. Retrieved from http://www.americangaming.org/sites/default/files/uploads/docs/aga_sos2013_fnl.pdf.

Baum, W. M. (1974). On two types of deviation from the matching law: Bias and undermatching. Journal of the Experimental Analysis of Behavior, 22, 231-242.

Baum, W. M. (1979). Matching, undermatching, and overmatching in studies of choice. Journal of the Experimental Analysis of Behavior, 32, 269-281.

Baum, W. M., \& Rachlin, H. C. (1969). Choice as time allocation. Journal of the Experimental Analysis of Behavior, 12, 861-874.

Berg, M. E., \& Grace, R. C. (2004). Independence of terminal-link entry rate and immediacy in concurrent chains. Journal of the Experimental Analysis of Behavior, 82, 235-251.

Clark, L., Crooks, B., Clarke, R., Aitken, M. F., \& Dunn, B. D. (2012). Physiological responses to near-miss outcomes and personal control during simulated gambling. Journal of Gambling Studies, 28, 123-137.

Côté, D., Caron, A., Aubert, J., Desrochers, V., \& Ladouceur, R. (2003). Near wins prolong gambling on a video lottery terminal. Journal of Gambling Studies, 19, 433-438.

Dixon, M. J., MacLaren, V., Jarick, M., Fugelsang, J. A., \& Harrigan, K. A. (2013). The frustrating effects of just missing the jackpot: Slot machine near-misses trigger large skin 
conductance responses, but no post-reinforcement pauses. Journal of Gambling Studies, 29, 661-674.

Dixon, M. R., \& Schreiber, J. E. (2004). Near-miss effects on response latencies and win estimations of slot machine players. The Psychological Record, 54, 335-348.

Dixon, M. R., MacLin, O. H., \& Daugherty, D. (2006). An evaluation of response allocations to concurrently available slot machine simulations. Behavior Research Methods, 38, 232236.

Fleshler, M., \& Hoffman, H. S. (1962). A progression for generating variable-interval schedules. Journal of the Experimental Analysis of Behavior, 5, 529-530.

Grace, R. C. (1994). A contextual model of concurrent-chains choice. Journal of the Experimental Analysis of Behavior, 61, 113-129.

Grace, R. C., \& Hucks, A. D. (2013). The allocation of operant behavior. In G. J. Madden, W. V. Dube, T. D. Hackenberg, G. P. Hanley, K. A. Lattal (Eds.), APA handbook of behavior analysis, Vol. 1: Methods and principles (pp. 307-337). Washington, DC, US: American Psychological Association.

Harris, A. C., Pentel, P. R., \& LeSage, M. G. (2007). Prevalence, magnitude, and correlates of an extinction burst in drug-seeking behavior in rats trained to self-administer nicotine during unlimited access (23 h/day) sessions. Psychopharmacology, 194, 395-402.

Kassinove, J. I., \& Schare, M. L. (2001). Effects of the 'near miss' and the 'big win' on persistence at slot machine gambling. Psychology of Addictive Behaviors, 15, 155-158.

Kyonka, E. G. E., \& Grace, R. C. (2008). Rapid acquisition of preference in concurrent chains when alternatives differ on multiple dimensions of reinforcement. Journal of the Experimental Analysis of Behavior, 89, 49-69. 
Kyonka, E. G. E., Rice, N., \& Ward, A. (2014). Discrimination and generalization in a pigeon slot machine analog. Manuscript in preparation.

Laude, J. R., Beckmann, J. S., Daniels, C. W., \& Zentall, T. R. (2014). Impulsivity affects suboptimal gambling-like choice by pigeons. Journal of Experimental Psychology: Animal Learning and Cognition, 40, 2-11.

Laude, J. R., Pattison, K. F., \& Zentall, T. R. (2012). Hungry pigeons make suboptimal choices, less hungry pigeons do not. Psychonomic Bulletin \& Review, 19, 884-891.

Laude, J. R., Stagner, J. P., \& Zentall, T. R. (2014). Suboptimal choice by pigeons may result from the diminishing effect of nonreinforcement. Journal of Experimental Psychology: Animal Learning and Cognition, 40(1), 12-21.

MacLin, O., Dixon, M. R., Daugherty, D., \& Small, S. L. (2007). Using a computer simulation of three slot machines to investigate a gambler's preference among varying densities of nearmiss alternatives. Behavior Research Methods, 39, 237-241.

Madden, G. J., Ewan, E. E., \& Lagorio, C. H. (2007). Toward an animal model of gambling: Delay discounting and the allure of unpredictable outcomes. Journal of Gambling Studies, 23, 63-83.

Mazur, J. E. (2001). Hyperbolic value addition and general models of animal choice. Psychological Review, 108, 96-112.

Nevin, J. A. (2012). Resistance to extinction and behavioral momentum. Behavioural Processes, 90, 89-97.

Nevin, J. A., Mandell, C., \& Atak, J. R. (1983). The analysis of behavioral momentum. Journal of the Experimental Analysis of Behavior, 39, 49-59. 
Peters, H., Hunt, M., \& Harper, D. (2010). An animal model of slot machine gambling: The effect of structural characteristics on response latency and persistence. Journal of Gambling Studies, 26, 521-531.

Raylu, N., \& Oei, T. S. (2002). Pathological gambling: A comprehensive review. Clinical Psychology Review, 22, 1009-1061.

Shaffer, H. J., Hall, M. N., \& Vander Bilt, J. (1999). Estimating the prevalence of disordered gambling behavior in the United States and Canada: A research synthesis. American Journal of Public Health, 89, 1369-1376.

Shahan, T. A. (2010). Conditioned reinforcement and response strength. Journal of the Experimental Analysis of Behavior, 93, 269-289.

Skinner, B. F. (1953). Science and human behavior. New York, NY: Appleton-Century-Crofts. Stagner, J. P., \& Zentall, T. R. (2010). Suboptimal choice behavior by pigeons. Psychonomic Bulletin \& Review, 17, 412-416.

Strickland, L. H., \& Grote, F. F. (1967). Temporal presentation of winning symbols and slotmachine playing. Journal of Experimental Psychology, 74, 10-13.

Welte, J. W., Barnes, G. M., Tidwell, M. O., \& Hoffman, J. H. (2008). The prevalence of problem gambling among U.S. adolescents and young adults: Results from a national survey. Journal of Gambling Studies, 24, 119-133.

Williams, B. A. (1994a). Conditioned reinforcement: Neglected or outmoded explanatory construct? Psychonomic Bulletin \& Review, 1, 457-475.

Williams, B. A. (1994b). Conditioned reinforcement: Experimental and theoretical issues. The Behavior Analyst, 17, 261-285. 
Winstanley, C. A., Cocker, P. J., \& Rogers, R. D. (2011). Dopamine modulates reward expectancy during performance of a slot machine task in rats: Evidence for a 'near-miss' effect. Neuropsychopharmacology, 36, 913-925. 
Table 1

Number of sessions in each condition for all pigeons in Experiment 1. Baseline, near-win present extinction (EXT:NWP), and near-win absent extinction (EXT:NWA) conditions occur in different orders for group $A$ and group $B$.

\begin{tabular}{cccccccc} 
& \multicolumn{2}{c}{ Pigeon (Group A) } & & & \multicolumn{3}{c}{ Pigeon (Group B) } \\
\cline { 2 - 3 } \cline { 5 - 7 } Condition & 301 & 401 & & Condition & 302 & 402 & 403 \\
\hline \hline Baseline & 26 & 26 & & Baseline & 26 & 26 & 26 \\
\hline EXT: NWP & 6 & 5 & & EXT: NWA & 5 & 6 & 7 \\
Baseline & 25 & 25 & & Baseline & 24 & 25 & 24 \\
EXT: NWA & 8 & 4 & & EXT: NWP & 8 & 8 & 3 \\
Baseline & 28 & 30 & & Baseline & 28 & 28 & 30 \\
EXT: NWP & 8 & 6 & & EXT: NWA & 8 & 8 & 8 \\
Baseline & 23 & 25 & & Baseline & 23 & 23 & 22 \\
EXT: NWA & 8 & 8 & & EXT: NWP & 8 & 8 & 8 \\
\hline
\end{tabular}


Table 2

Mean number of omissions in the final five baseline sessions for each baseline condition for all pigeons in Experiment 1. Each baseline condition occurred prior to either a near-win present or near-win absent extinction condition, depending on the group assignment for each pigeon.

Standard deviations are noted in parentheses.

Trial Type

\begin{tabular}{|c|c|c|c|c|}
\hline Pigeon & Clear Loss & Loss & Near Win & Win \\
\hline \multirow[t]{4}{*}{301} & $79(2)$ & $76.2(2.39)$ & $58.2(4.32)$ & $0(0)$ \\
\hline & $83.2(2.39)$ & $79.2(1.3)$ & $61(2.74)$ & $0(0)$ \\
\hline & $82.8(2.77)$ & $77.6(1.52)$ & $58.6(6.69)$ & $0(0)$ \\
\hline & $86.2(2.17)$ & $83.2(2.86)$ & $64.6(4.98)$ & $0(0)$ \\
\hline \multirow[t]{4}{*}{302} & $60.4(7.02)$ & $56.8(5.07)$ & $39.4(7.37)$ & $0.2(0.45)$ \\
\hline & $87.8(1.92)$ & $84.4(2.3)$ & $74.8(1.1)$ & $0(0)$ \\
\hline & $78.6(11.01)$ & $76.2(10.62)$ & $63.8(6.38)$ & $0.2(0.45)$ \\
\hline & 76.2 (14.94) & $74.4(13.33)$ & $86.8(10.35)$ & $0.8(1.79)$ \\
\hline \multirow[t]{4}{*}{401} & $90.2(1.92)$ & $83.6(2.7)$ & $54.4(7.67)$ & $0.4(0.89)$ \\
\hline & 48.2 (19.89) & $40.2(13.66)$ & $28.8(14.2)$ & $0.6(0.89)$ \\
\hline & $90.6(1.82)$ & $86.8(4.09)$ & $63.4(1.82)$ & $2.4(1.14)$ \\
\hline & $70(10.34)$ & $59(9.7)$ & $41.6(9.04)$ & $2.2(1.64)$ \\
\hline \multirow[t]{4}{*}{402} & $74.6(2.88)$ & $72(2.55)$ & $60(3.39)$ & $0(0)$ \\
\hline & $70.4(6.02)$ & $72(4.64)$ & $55.2(4.09)$ & $0(0)$ \\
\hline & 60.8 (11.69) & $59.2(10.69)$ & $46(10.75)$ & $0(0)$ \\
\hline & $82.4(2.88)$ & $82.4(3.21)$ & $61(3.46)$ & $0.2(0.45)$ \\
\hline \multirow[t]{4}{*}{403} & $64.6(8.26)$ & $65(9.49)$ & $49(5.87)$ & $0(0)$ \\
\hline & $71.8(6.87)$ & $72.2(5.26)$ & $64.8(3.11)$ & $0(0)$ \\
\hline & $17.8(5.07)$ & $16.6(5.03)$ & $14.8(4.76)$ & $0(0)$ \\
\hline & $70.2(5.67)$ & $70.6(6.5)$ & $65.6(5.81)$ & $0(0)$ \\
\hline
\end{tabular}


Table 3

Number of trials for each trial type (clear loss, near win, win) shown in a 30-trial block for each component.

\begin{tabular}{lccc} 
& \multicolumn{3}{c}{ Number of Trials per Block } \\
\cline { 2 - 4 } Component & Clear Loss & Near Win & Win \\
\hline \hline Certain & 0 & 0 & 30 \\
\hline Probabilistic & 20 & 0 & 10 \\
\hline Gambling & 10 & 10 & 10
\end{tabular}


Table 4.1

Order of conditions and components for Pigeon 303. Magazine presentations denote the number of times the food magazine was activated for $2.5 \mathrm{~s}$ during each reinforcer delivery. The richer component in each condition is italicized.

Pigeon 303

\begin{tabular}{ccccccc}
\hline & \multicolumn{2}{c}{ Left Key } & & \multicolumn{2}{c}{ Right Key } & \\
\cline { 2 - 3 } Condition & Component & $\begin{array}{c}\text { Magazine } \\
\text { Pres. }\end{array}$ & & Component & $\begin{array}{c}\text { Magazine } \\
\text { Pres. }\end{array}$ & $\begin{array}{c}\text { Log Reinforcer } \\
\text { Ratio } \\
\text { (Left/Right) }\end{array}$ \\
\hline \hline 1 & Certain & 2 & & Probabilistic & 6 & 0 \\
\hline 2 & Certain & 3 & & Probabilistic & 3 & 0.48 \\
\hline 3 & Certain & 1 & & Probabilistic & 9 & -0.48 \\
\hline 4 & Probabilistic & 9 & & Gambling & 3 & 0.48 \\
\hline 5 & Probabilistic & 3 & & Gambling & 9 & -0.48 \\
\hline 6 & Probabilistic & 6 & & Gambling & 6 & 0 \\
\hline 7 & Gambling & 3 & & Certain & 3 & -0.48 \\
\hline 8 & Gambling & 6 & & Certain & 2 & 0 \\
\hline 9 & Gambling & 9 & Certain & 1 & 0.48 \\
\hline
\end{tabular}


Table 4.2

Order of conditions and components for Pigeon 305. Magazine presentations denote the number of times the food magazine was activated for $2.5 \mathrm{~s}$ during each reinforcer delivery. The richer component in each condition is italicized.

Pigeon 305

\begin{tabular}{ccccccc}
\hline & \multicolumn{2}{c}{ Left Key } & & \multicolumn{2}{c}{ Right Key } & \\
\cline { 2 - 3 } Condition & Component & $\begin{array}{c}\text { Magazine } \\
\text { Pres. }\end{array}$ & & Component & $\begin{array}{c}\text { Magazine } \\
\text { Pres. }\end{array}$ & $\begin{array}{c}\text { Log Reinforcer } \\
\text { Ratio } \\
\text { (Left/Right) }\end{array}$ \\
\hline \hline 1 & Probabilistic & 2 & & Gambling & 6 & 0 \\
\hline 2 & Probabilistic & 1 & & Gambling & 9 & -0.48 \\
\hline 3 & Probabilistic & 3 & & Gambling & 3 & 0.48 \\
\hline 4 & Gambling & 3 & & Certain & 3 & -0.48 \\
\hline 5 & Gambling & 9 & & Certain & 1 & 0.48 \\
\hline 6 & Gambling & 6 & & Certain & 2 & 0 \\
\hline 7 & Certain & 9 & & Probabilistic & 3 & 0.48 \\
\hline 8 & Certain & 6 & Probabilistic & 6 & 0 \\
\hline 9 & Certain & 3 & Probabilistic & 9 & -0.48 \\
\hline
\end{tabular}


Table 4.3

Order of conditions and components for Pigeon 306. Magazine presentations denote the number of times the food magazine was activated for $2.5 \mathrm{~s}$ during each reinforcer delivery. The richer component in each condition is italicized.

Pigeon 306

\begin{tabular}{ccccccc}
\hline & \multicolumn{2}{c}{ Left Key } & & \multicolumn{2}{c}{ Right Key } & \\
\cline { 2 - 3 } Condition & Component & $\begin{array}{c}\text { Magazine } \\
\text { Pres. }\end{array}$ & & Component & $\begin{array}{c}\text { Magazine } \\
\text { Pres. }\end{array}$ & $\begin{array}{c}\text { Log Reinforcer } \\
\text { Ratio } \\
\text { (Left/Right) }\end{array}$ \\
\hline \hline 1 & Gambling & 9 & & Certain & 1 & 0.48 \\
\hline 2 & Gambling & 3 & & Certain & 3 & -0.48 \\
\hline 3 & Gambling & 6 & & Certain & 2 & 0 \\
\hline 4 & Certain & 1 & & Probabilistic & 9 & -0.48 \\
\hline 5 & Certain & 2 & & Probabilistic & 6 & 0 \\
\hline 6 & Certain & 3 & & Probabilistic & 3 & 0.48 \\
\hline 7 & Probabilistic & 6 & & Gambling & 6 & 0 \\
\hline 8 & Probabilistic & 9 & & Gambling & 3 & 0.48 \\
\hline 9 & Probabilistic & 3 & & Gambling & 9 & -0.48 \\
\hline
\end{tabular}


Table 5

Bias parameters and 95\% confidence intervals for all pigeons and all pairwise comparisons in Experiment 2. Eight out of nine biases were significantly different from zero (Pigeon 305, C vs. $P$ comparison was not). Each component is denoted by a letter abbreviation - Certain $(C)$, Probabilistic $(P)$, and Gambling $(G)$. A positive bias indicates a preference for the component listed first and a negative bias indicates a preference for the component listed second.

\section{Pigeons}

Pairwise Comparison 303 305 306

\begin{tabular}{cccc}
\hline \hline C vs. P & $0.32[0.25,0.36]$ & $0.02[-0.06,0.23]$ & $-0.61[-0.69,-0.47]$ \\
\hline P vs. G & $0.20[0.13,0.22]$ & $-0.09[-0.22,-0.05]$ & $0.20[0.02,0.37]$ \\
\hline C vs. G & $-0.20[-0.30,-0.10]$ & $-0.56[-0.60,-0.52]$ & $-0.46[-0.57,-0.40]$ \\
\hline
\end{tabular}


Table 6

Mean number of omission trials for pairwise comparison. Means were calculated using the last five sessions of each condition and were collapsed across reinforcer ratios. The component types and their associated trial types are labeled.

\begin{tabular}{ccccccc}
\hline \multicolumn{7}{c}{ Pigeon 303} \\
$\begin{array}{c}\text { Pairwise } \\
\text { Comparison }\end{array}$ & $\begin{array}{c}\text { Certain: } \\
\text { Win }\end{array}$ & $\begin{array}{c}\text { Prob.: } \\
\text { Clear } \\
\text { Loss }\end{array}$ & $\begin{array}{c}\text { Prob.: } \\
\text { Win }\end{array}$ & $\begin{array}{c}\text { Gambling: } \\
\text { Clear } \\
\text { Loss }\end{array}$ & $\begin{array}{c}\text { Gambling: } \\
\text { Near Win }\end{array}$ & $\begin{array}{c}\text { Gambling: } \\
\text { Win }\end{array}$ \\
\hline \hline vs. Certain & - & 63.7 & 0.7 & 35.9 & 34.3 & 2.1 \\
vs. Prob. & 1.3 & - & - & 30 & 15.4 & 1 \\
\hline vs. Gambling & 2.3 & 59.3 & 2.1 & - & - & -
\end{tabular}

\begin{tabular}{ccccccc}
\hline \multicolumn{7}{c}{ Pigeon 305 } \\
$\begin{array}{c}\text { Pairwise } \\
\text { Comparison }\end{array}$ & $\begin{array}{c}\text { Certain: } \\
\text { Win }\end{array}$ & $\begin{array}{c}\text { Prob.: } \\
\text { Clear } \\
\text { Loss }\end{array}$ & $\begin{array}{c}\text { Prob.: } \\
\text { Win }\end{array}$ & $\begin{array}{c}\text { Gambling: } \\
\text { Clear } \\
\text { Loss }\end{array}$ & $\begin{array}{c}\text { Gambling: } \\
\text { Near Win }\end{array}$ & $\begin{array}{c}\text { Gambling: } \\
\text { Win }\end{array}$ \\
\hline \hline vs. Certain & - & 47.3 & 0 & 18.9 & 8.8 & 1.3 \\
\hline vs. Prob. & 1.9 & - & - & 26.5 & 15.1 & 0.3 \\
\hline vs. Gambling & 2.7 & 52 & 0.3 & - & - & -
\end{tabular}

\begin{tabular}{ccccccc}
\multicolumn{7}{c}{ Pigeon 306 } \\
$\begin{array}{c}\text { Pairwise } \\
\text { Comparison }\end{array}$ & $\begin{array}{c}\text { Certain: } \\
\text { Win }\end{array}$ & $\begin{array}{c}\text { Prob.: } \\
\text { Clear } \\
\text { Loss }\end{array}$ & $\begin{array}{c}\text { Prob.: } \\
\text { Win }\end{array}$ & $\begin{array}{c}\text { Gambling: } \\
\text { Clear } \\
\text { Loss }\end{array}$ & $\begin{array}{c}\text { Gambling: } \\
\text { Near Win }\end{array}$ & $\begin{array}{c}\text { Gambling: } \\
\text { Win }\end{array}$ \\
\hline \hline vs. Certain & - & 58.7 & 0.3 & 30 & 16.9 & 1 \\
\hline vs. Prob. & 0.6 & - & - & 31.1 & 14.1 & 0 \\
\hline vs. Gambling & 1.3 & 58.5 & 0 & - & - & -
\end{tabular}


Table 7

Order of conditions and near-win probabilities for all subjects in Experiment 3. Reinforcers per win denote the number of times the hopper was activated for $2.5 s$ during each reinforcer delivery.

Pigeon 303

\begin{tabular}{|c|c|c|c|c|c|c|}
\hline \multirow[b]{2}{*}{ Condition } & \multicolumn{2}{|c|}{ Left Key } & \multicolumn{2}{|c|}{ Right Key } & \multirow[b]{2}{*}{$\begin{array}{l}\text { Near-Win } \\
\text { Probability }\end{array}$} & \multirow[b]{2}{*}{$\begin{array}{c}\log \\
\text { Reinforcer } \\
\text { Ratio }\end{array}$} \\
\hline & Component & $\begin{array}{l}\text { Magazine } \\
\text { Pres. }\end{array}$ & Component & $\begin{array}{l}\text { Magazine } \\
\text { Pres. }\end{array}$ & & \\
\hline 1 & Certain & 3 & Gambling & 3 & $7 \%$ & 0.48 \\
\hline 2 & Certain & 1 & Gambling & 9 & $7 \%$ & -0.48 \\
\hline 3 & Certain & 3 & Gambling & 3 & $17 \%$ & 0.48 \\
\hline 4 & Certain & 1 & Gambling & 9 & $17 \%$ & -0.48 \\
\hline
\end{tabular}

Pigeon 305

\begin{tabular}{|c|c|c|c|c|c|c|}
\hline \multirow[b]{2}{*}{ Condition } & \multicolumn{2}{|c|}{ Left Key } & \multicolumn{2}{|c|}{ Right Key } & \multirow[b]{2}{*}{$\begin{array}{l}\text { Near-Win } \\
\text { Probability }\end{array}$} & \multirow[b]{2}{*}{$\begin{array}{c}\text { Log } \\
\text { Reinforcer } \\
\text { Ratio }\end{array}$} \\
\hline & Component & $\begin{array}{c}\text { Magazine } \\
\text { Pres. }\end{array}$ & Component & $\begin{array}{c}\text { Magazine } \\
\text { Pres. }\end{array}$ & & \\
\hline 1 & Gambling & 9 & Certain & 1 & $17 \%$ & 0.48 \\
\hline 2 & Gambling & 3 & Certain & 3 & $17 \%$ & -0.48 \\
\hline 3 & Gambling & 9 & Certain & 1 & $7 \%$ & 0.48 \\
\hline 4 & Gambling & 3 & Certain & 3 & $7 \%$ & -0.48 \\
\hline
\end{tabular}

Pigeon 306

\begin{tabular}{|c|c|c|c|c|c|c|}
\hline \multirow[b]{2}{*}{ Condition } & \multicolumn{2}{|c|}{ Left Key } & \multicolumn{2}{|c|}{ Right Key } & \multirow[b]{2}{*}{$\begin{array}{l}\text { Near-Win } \\
\text { Probability }\end{array}$} & \multirow[b]{2}{*}{$\begin{array}{c}\text { Log } \\
\text { Reinforcer } \\
\text { Ratio }\end{array}$} \\
\hline & Component & $\begin{array}{c}\text { Magazine } \\
\text { Pres. }\end{array}$ & Component & $\begin{array}{c}\text { Magazine } \\
\text { Pres. }\end{array}$ & & \\
\hline 1 & Gambling & 3 & Certain & 3 & $7 \%$ & -0.48 \\
\hline 2 & Gambling & 9 & Certain & 1 & $7 \%$ & 0.48 \\
\hline 3 & Gambling & 3 & Certain & 3 & $17 \%$ & -0.48 \\
\hline 4 & Gambling & 9 & Certain & 1 & $17 \%$ & 0.48 \\
\hline
\end{tabular}


Table 8

Bias parameters and 95\% confidence intervals for all pigeons and all conditions in Experiment

3. All biases were significantly different from zero. Positive bias indicates preference for the Certain component and negative bias indicates preference for the Gambling component.

Pigeons

\begin{tabular}{cccc}
$\begin{array}{c}\text { Near-Win } \\
\text { Probability }\end{array}$ & 303 & 305 & 306 \\
\hline \hline $0 \%$ & $0.36[0.27,0.40]$ & $0.17[0.13,0.34]$ & $-0.49[-0.51,-0.41]$ \\
$7 \%$ & $0.23[0.08,0.44]$ & $-0.71[-0.76,-0.61]$ & $-0.39[-0.45,-0.17]$ \\
\hline $17 \%$ & $0.05[0.004,0.11]$ & $-0.55[-0.69,-0.51]$ & $-0.60[-0.72,-0.49]$ \\
$33 \%$ & $-0.32[-0.37,-0.23]$ & $-0.53[-0.61,-0.50]$ & $-0.54[-0.79,-0.35]$ \\
\hline
\end{tabular}


Table 9

Mean number of omission trials for each near-win probability. Means were calculated using the last five sessions of each condition and were collapsed across reinforcer ratios. The component types and their associated trial types are labeled.

Pigeon 303

\begin{tabular}{ccccc}
\hline $\begin{array}{c}\text { Near-Win } \\
\text { Probability }\end{array}$ & $\begin{array}{c}\text { Certain: } \\
\text { Win }\end{array}$ & $\begin{array}{c}\text { Gambling: } \\
\text { Clear Loss }\end{array}$ & $\begin{array}{c}\text { Gambling: } \\
\text { Near Win }\end{array}$ & $\begin{array}{c}\text { Gambling: } \\
\text { Win }\end{array}$ \\
\hline \hline $0 \%$ & 1.5 & 61.1 & - & 0.5 \\
$7 \%$ & 5.7 & 61.1 & 4.4 & 1.7 \\
$17 \%$ & 3.1 & 51.3 & 11.7 & 2 \\
$33 \%$ & 2.5 & 35.4 & 34.1 & 2.1 \\
\hline
\end{tabular}

Pigeon 305

\begin{tabular}{ccccc}
\hline $\begin{array}{c}\text { Near-Win } \\
\text { Probability }\end{array}$ & $\begin{array}{c}\text { Certain: } \\
\text { Win }\end{array}$ & $\begin{array}{c}\text { Gambling: } \\
\text { Clear Loss }\end{array}$ & $\begin{array}{c}\text { Gambling: } \\
\text { Near Win }\end{array}$ & $\begin{array}{c}\text { Gambling: } \\
\text { Win }\end{array}$ \\
\hline \hline $0 \%$ & 1.2 & 46.7 & - & 0 \\
$7 \%$ & 2.7 & 41.4 & 2.5 & 2.3 \\
$17 \%$ & 2 & 48 & 6.5 & 0 \\
$33 \%$ & 3.4 & 15.5 & 7.3 & 1.5 \\
\hline
\end{tabular}

Pigeon 306

\begin{tabular}{ccccc}
\hline $\begin{array}{c}\text { Near-Win } \\
\text { Probability }\end{array}$ & $\begin{array}{c}\text { Certain: } \\
\text { Win }\end{array}$ & $\begin{array}{c}\text { Gambling: } \\
\text { Clear Loss }\end{array}$ & $\begin{array}{c}\text { Gambling: } \\
\text { Near Win }\end{array}$ & $\begin{array}{c}\text { Gambling: } \\
\text { Win }\end{array}$ \\
\hline \hline $0 \%$ & 0.8 & 59.1 & - & 0.5 \\
$7 \%$ & 0.5 & 51.8 & 1.8 & 1 \\
$17 \%$ & 0 & 44 & 7.9 & 0 \\
$33 \%$ & 1.5 & 29.7 & 15.3 & 1.5 \\
\hline
\end{tabular}




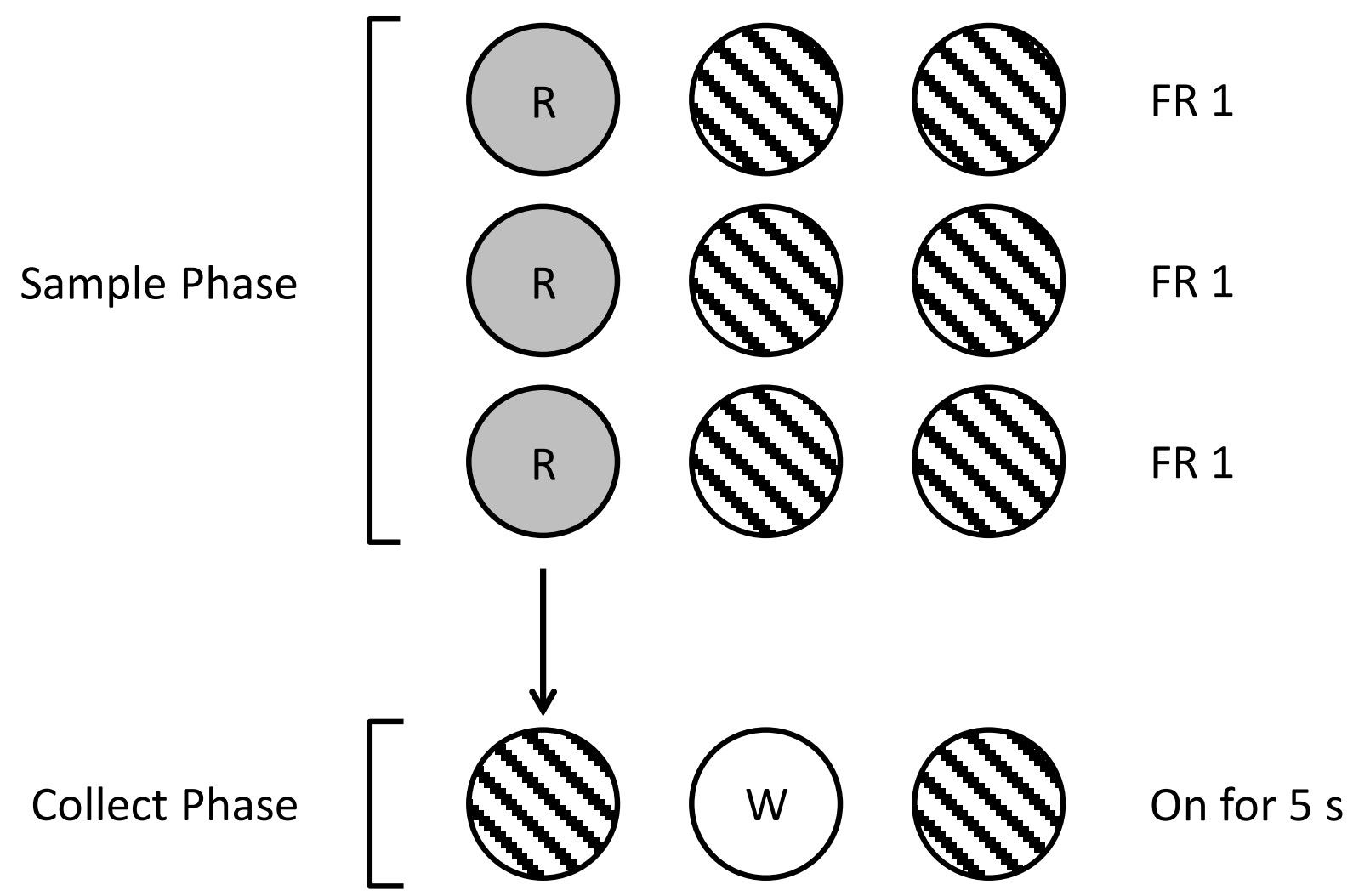

Figure 1. Diagram depicting the progression of a winning trial in Experiment 1. Each circle represents a key at the various stages in the chain schedule. The letters on the keys represent the color, white (W) or red (R). Dashed keys represent darkened or inactive keys. 


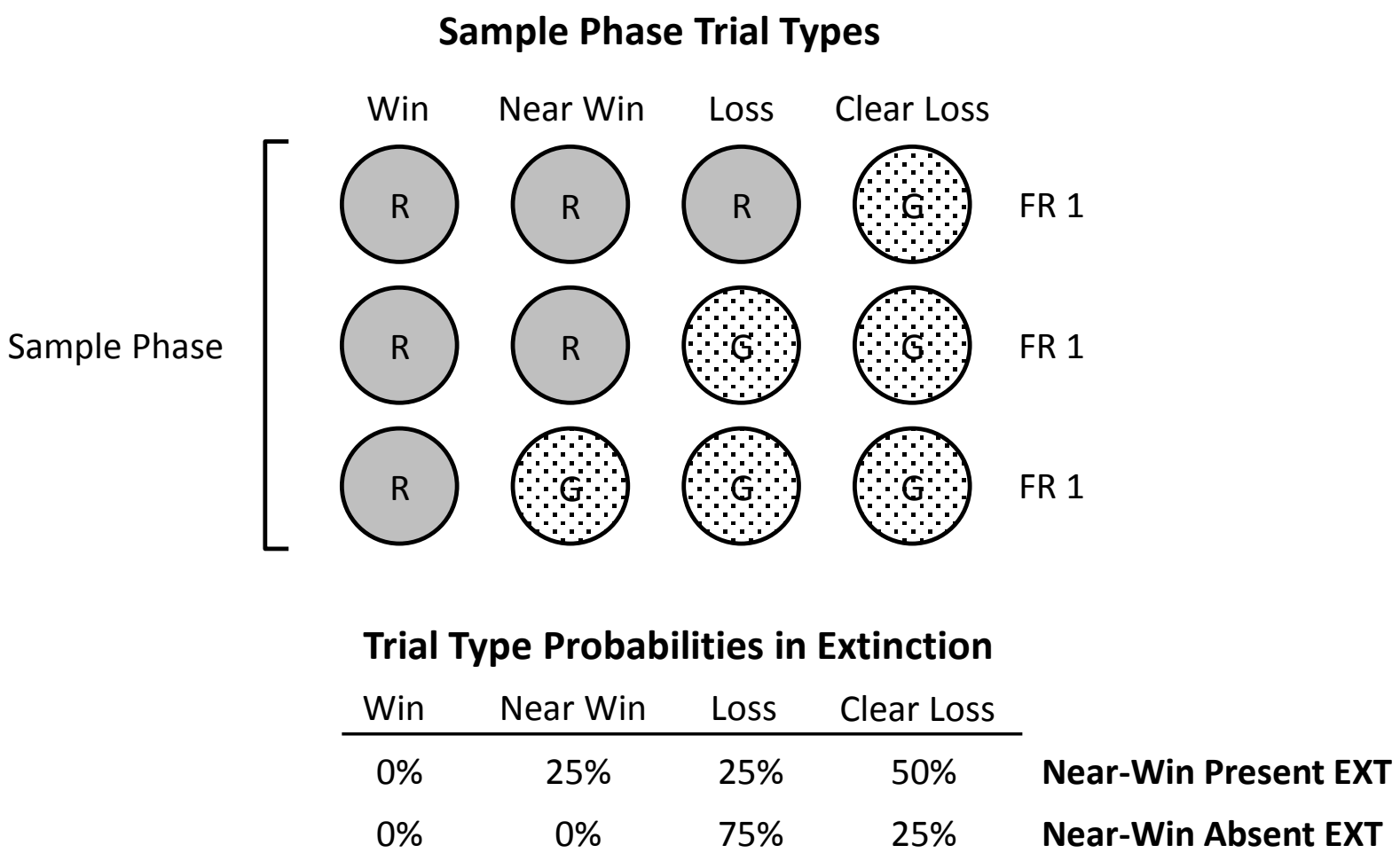

Figure 2. Sample-phase stimulus arrangement for trial types in Experiment 1. Each circle represents one of the key colors in the 3-color arrangement. The letters on the keys represent the color, red $(\mathrm{R})$ or green $(\mathrm{G})$. Each trial type was equiprobable in the experimental baseline of Experiment 1: the probability of any one trial being a particular trial type is $25 \%$. The probability of each trial type occurring in extinction condition is listed. 


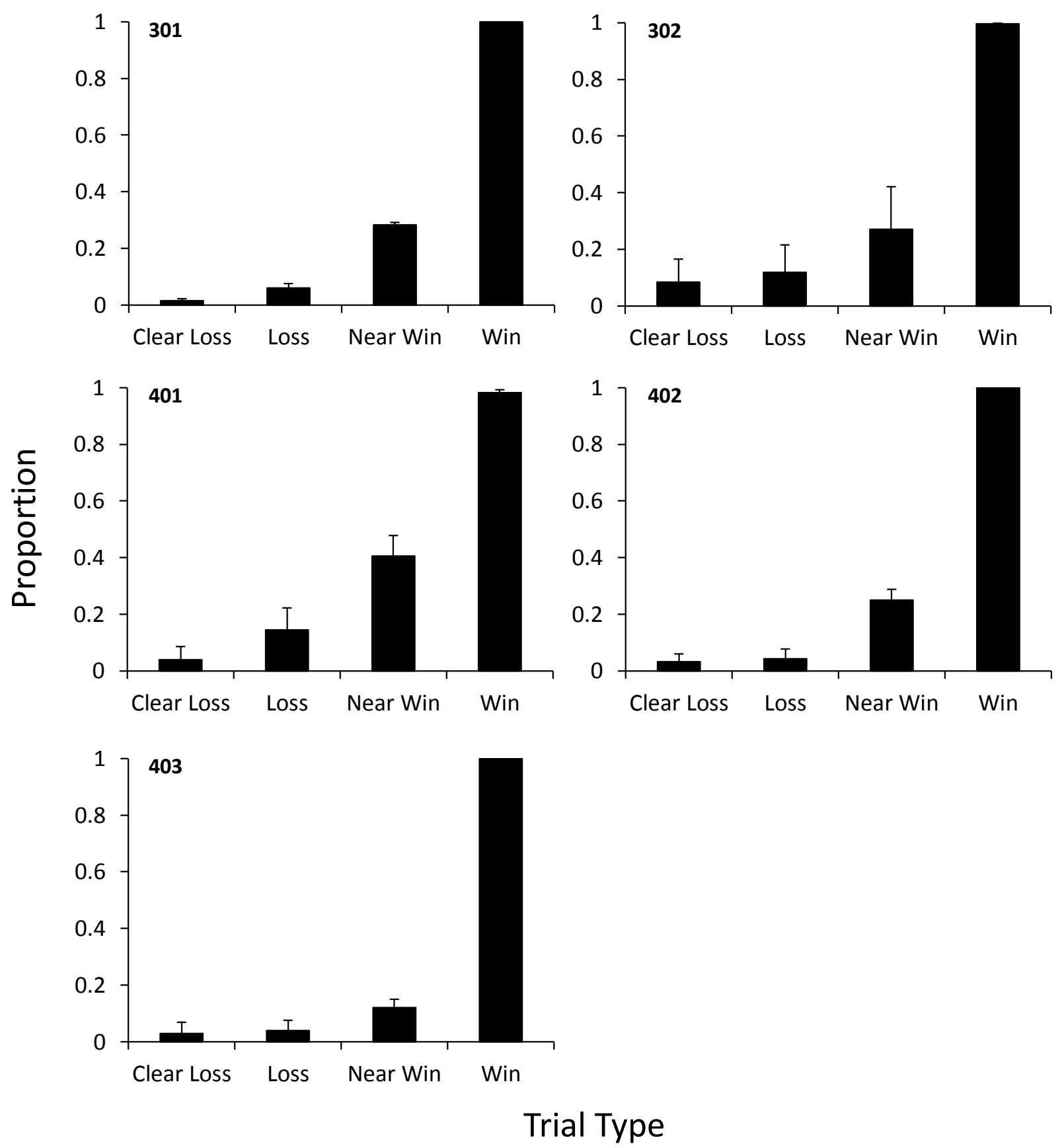

Figure 3. Mean proportion of trials where a peck occurred during the collect phase as a function of trial type in Experiment 1. Bars show means calculated from pooling the last five sessions of each baseline condition. Error bars represent standard deviation. 


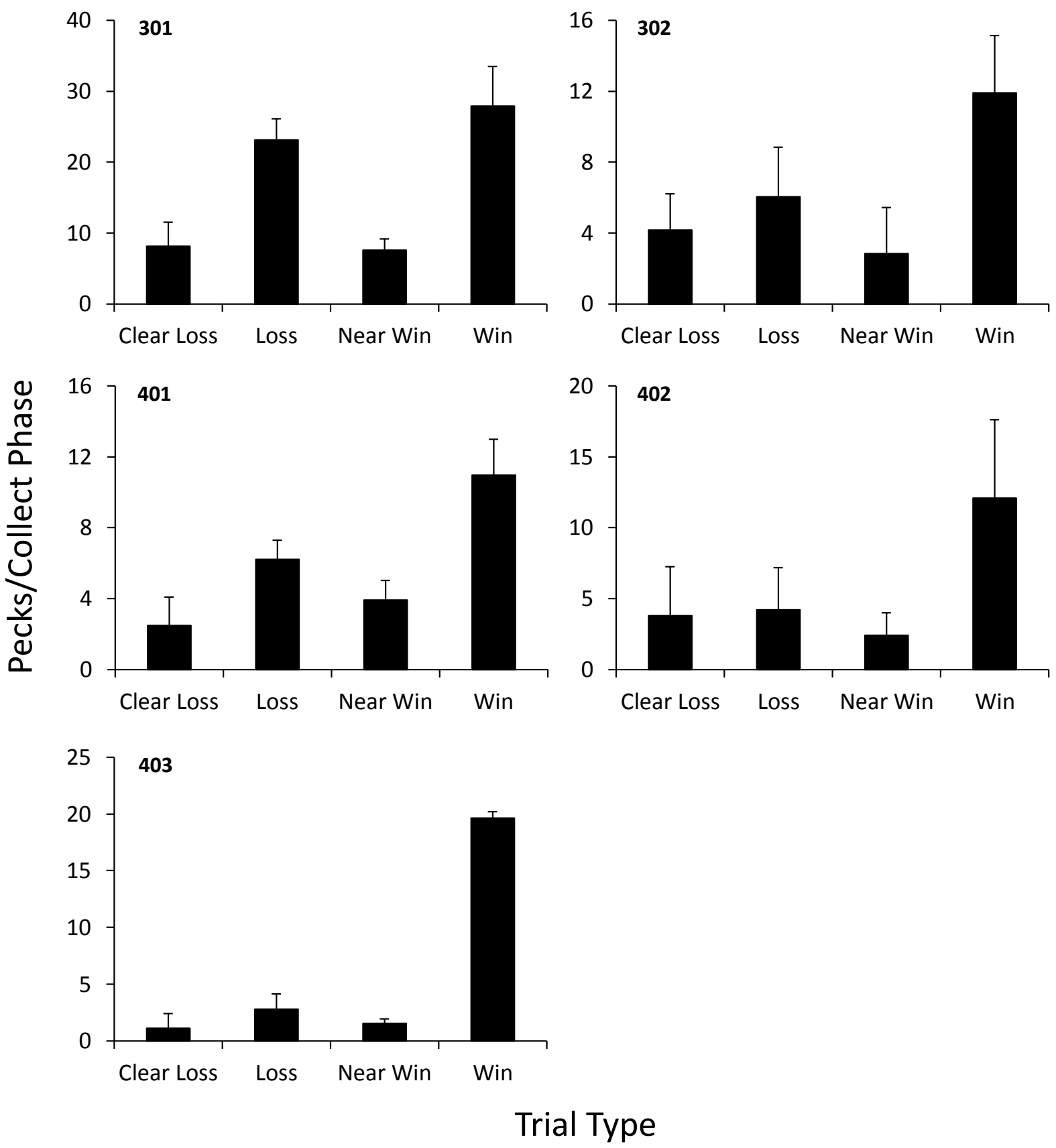

Figure 4. Mean pecks during the collect phase for trials where at least one peck occurred as a function of trial type in Experiment 1. Bars show means calculated from pooling the last five sessions of each baseline condition. Error bars represent standard deviation. 

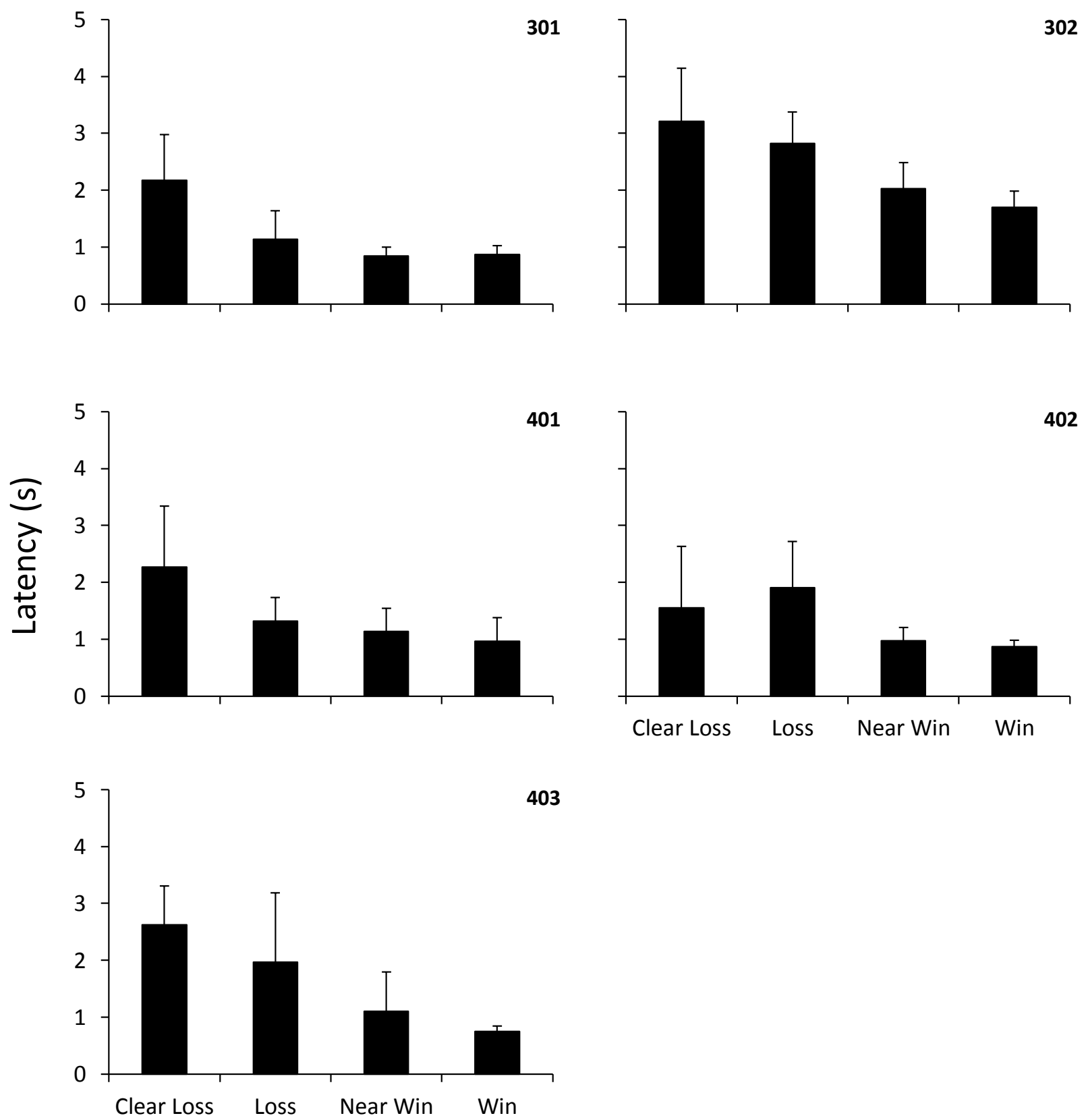

\section{Trial Type}

Figure 5. Mean of all median times to the first peck on the collect key from the last five baseline sessions of all baseline conditions for each trial type and each pigeon in Experiment 1. Trials where no pecks occurred in the collect phase were omitted from this analysis. Error bars represent the standard deviation. 

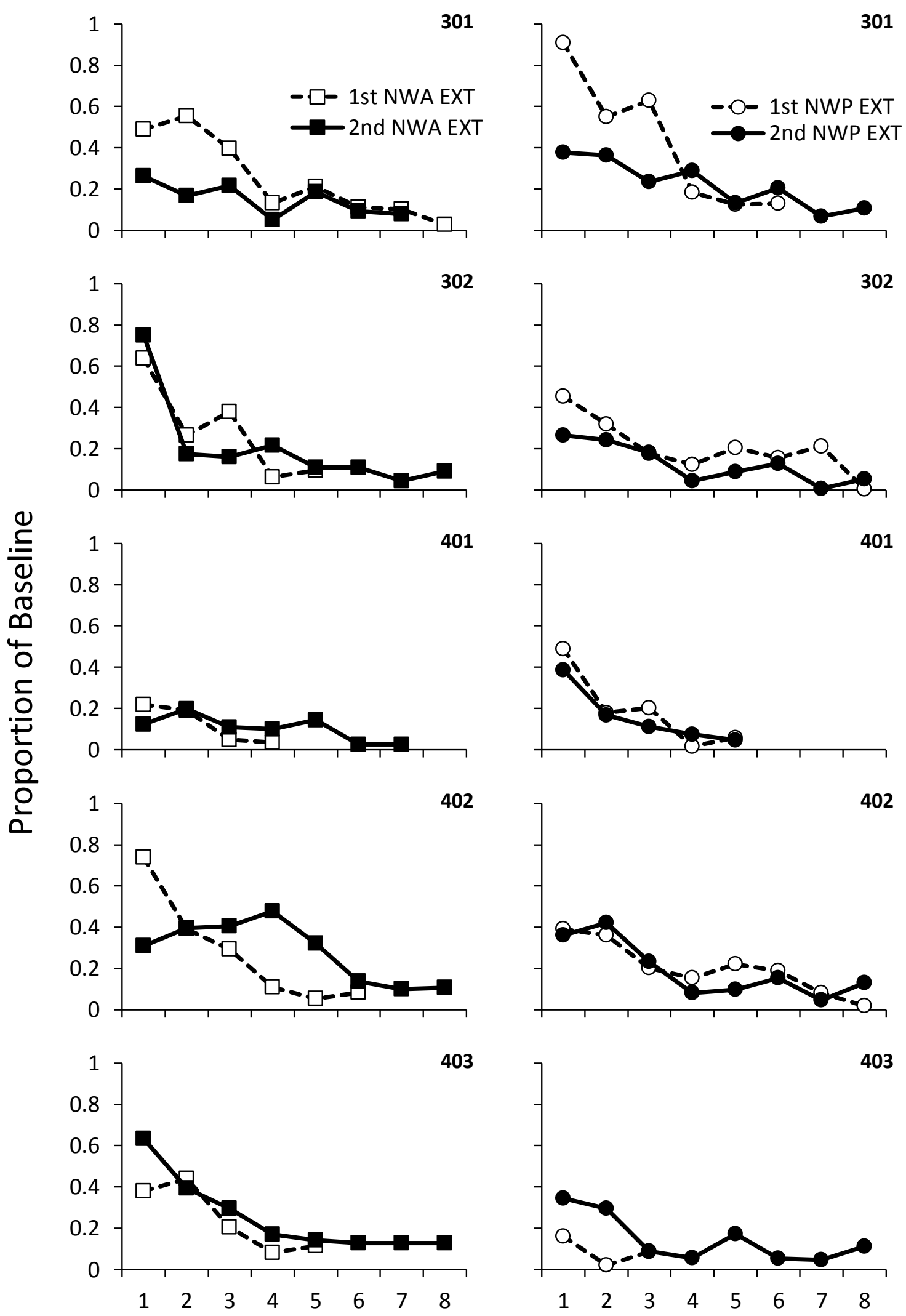

Extinction Session 
Figure 6. Number of trials completed across the different extinction conditions shown as a proportion of baseline for each pigeon (rows) in Experment 1. Proportions were calculated against the mean of the previous five baseline sessions. Each row represents a different pigeon and the leftmost panels show data from the near-win absent extinction conditions and the rightmost panels show data for the near-win present extinction conditions. The first extinction session for each condition type is shown as empty symbols and the second extinction condition is shown by filled symbols. Squares depict near-win absent extinction conditions and circles depict near-win present extinction conditions. 
Example Trial

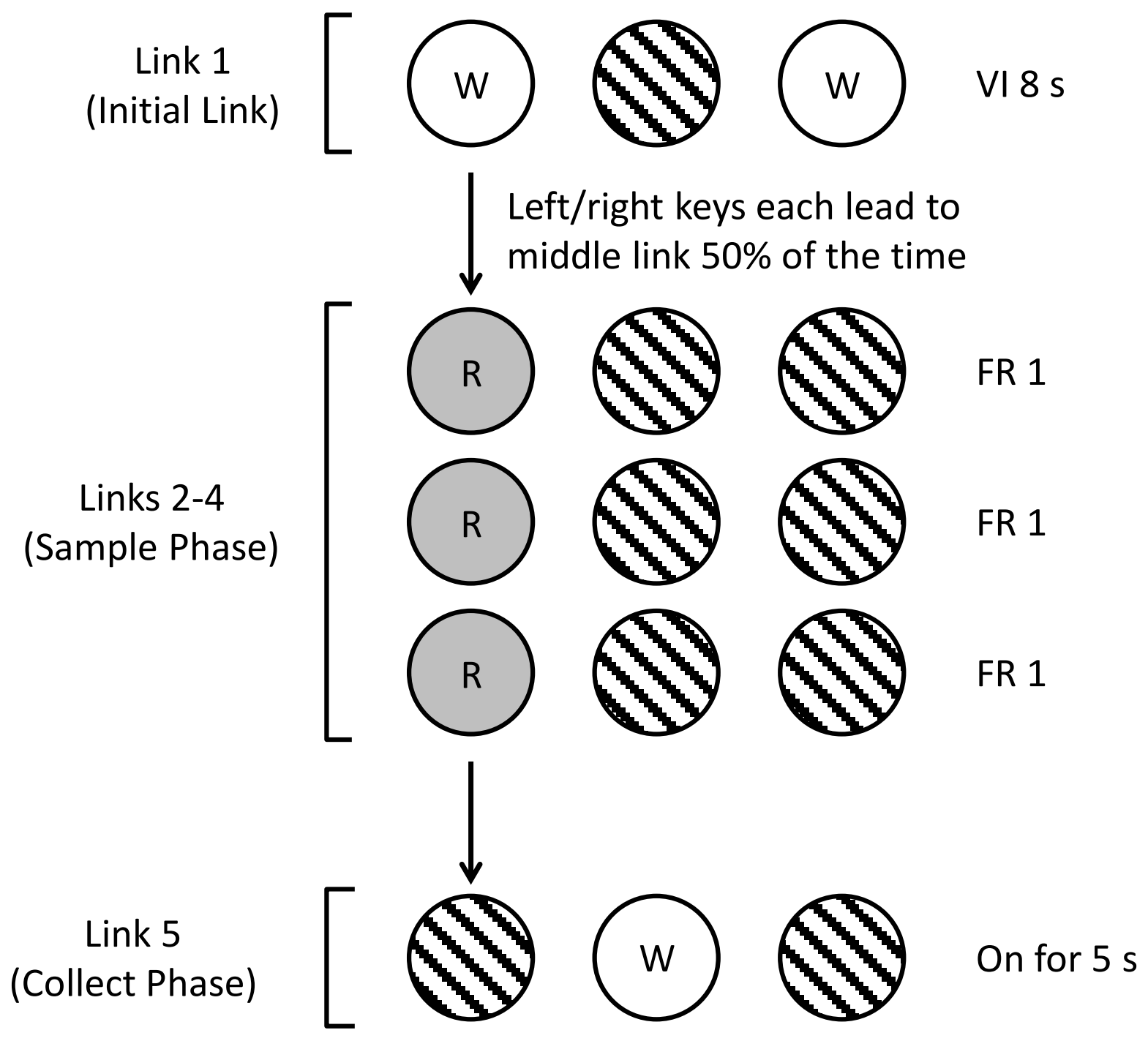

Figure 7. Diagram depicting the sequence of experimental events during a winning trial for Experiments 2 and 3. Each circle represents one of the three keys at the various stages in the concurrent-chains procedure. The order of links progresses from top to bottom. The letters on the keys represent the color, white (W) or red (R). Dashed keys represent darkened, inactive keys. 


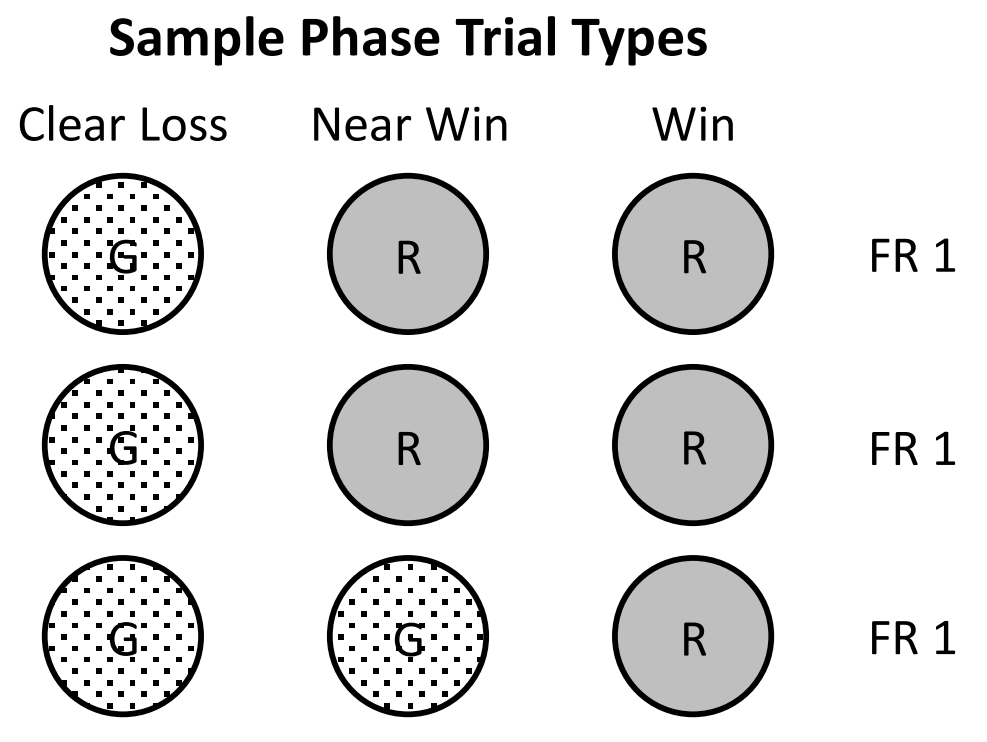

Figure 8. Possible trial types and the associated stimuli shown in the sample phase in

Experiments 2 and 3. Each circle represents one of the presentations in the three-link sequence.

The letters on the keys represent the color, red (R) or green $(G)$. 
Certain vs.

Probabilistic
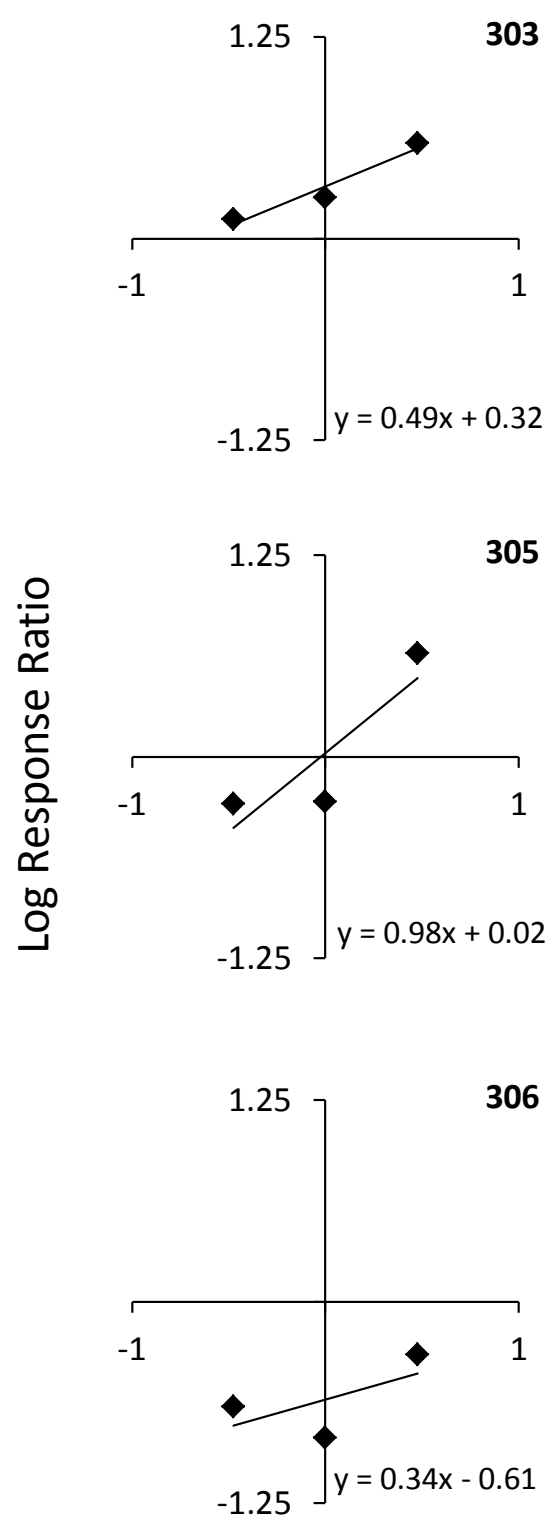

Certain vs.

Gambling
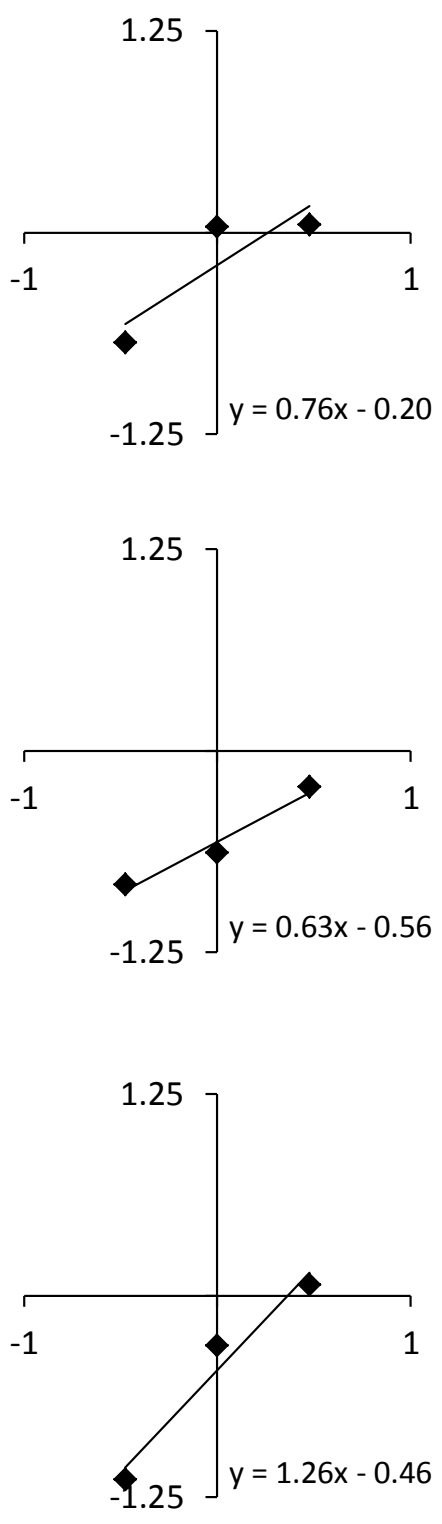

Log Reinforcer Ratio
Probabilistic vs.

Gambling
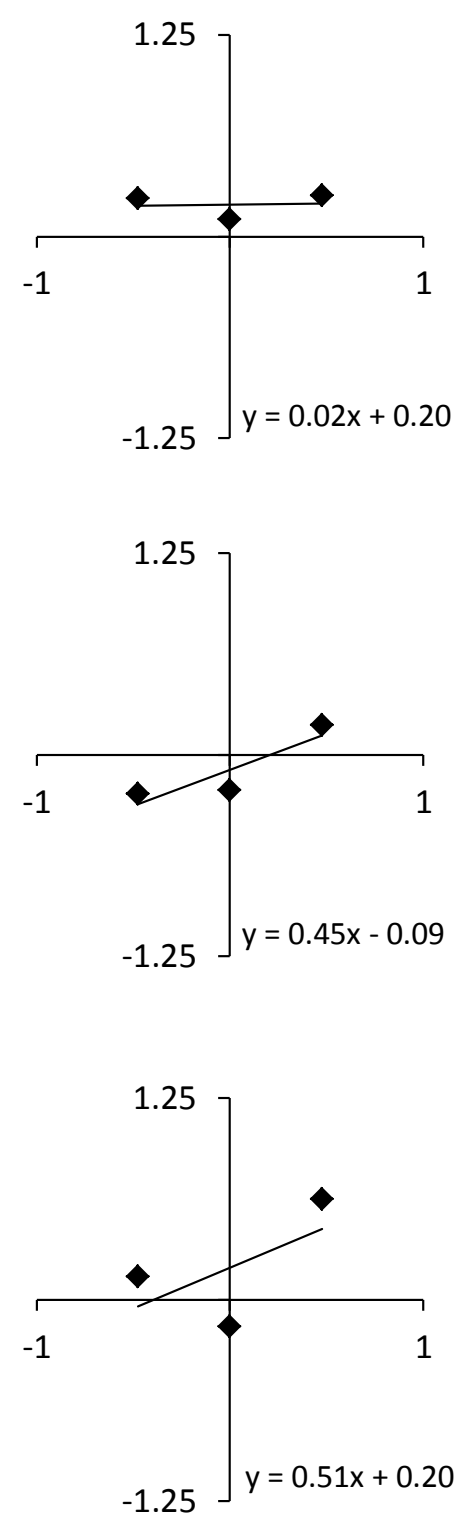
Figure 9. Matching law functions generated by Equation 1 for all conditions and phases (columns) for all subjects (rows) in Experiment 2. Data are shown as log response ratios as a function of log reinforcement ratio. Each column represents a separate pairwise comparison and each row represents a subject. Each panel has three data points which are indicative of the three $\log$ reinforcer ratios $(1: 3,1: 1,3: 1)$. The leftmost data point represents the $1: 3$ ratio, the middle data point represents the 1:1 ratio, and the rightmost data point represents the 3:1 ratio. Each data point represents a condition: 1:3 (leftmost), 1:1 (center), and 3:1 (rightmost). The line represents the line of best fit and its accompanying equation is shown in the bottom right of each panel. 
Certain
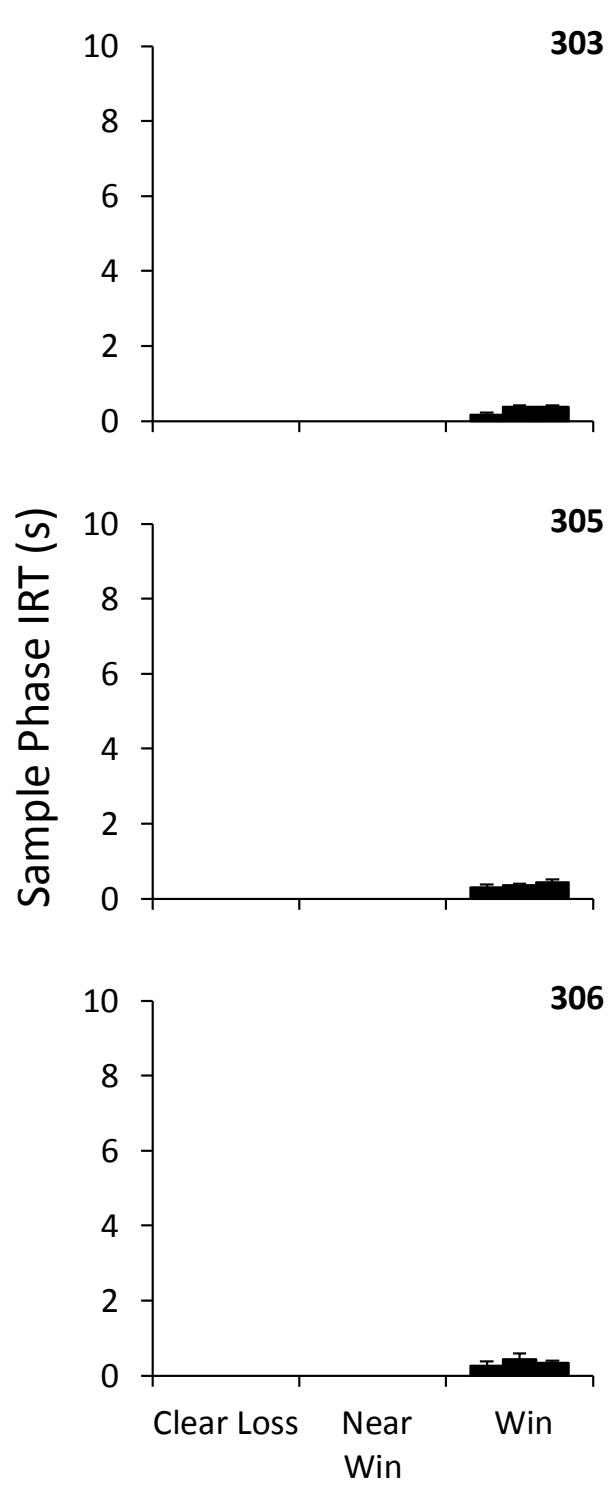

305
Probabilistic
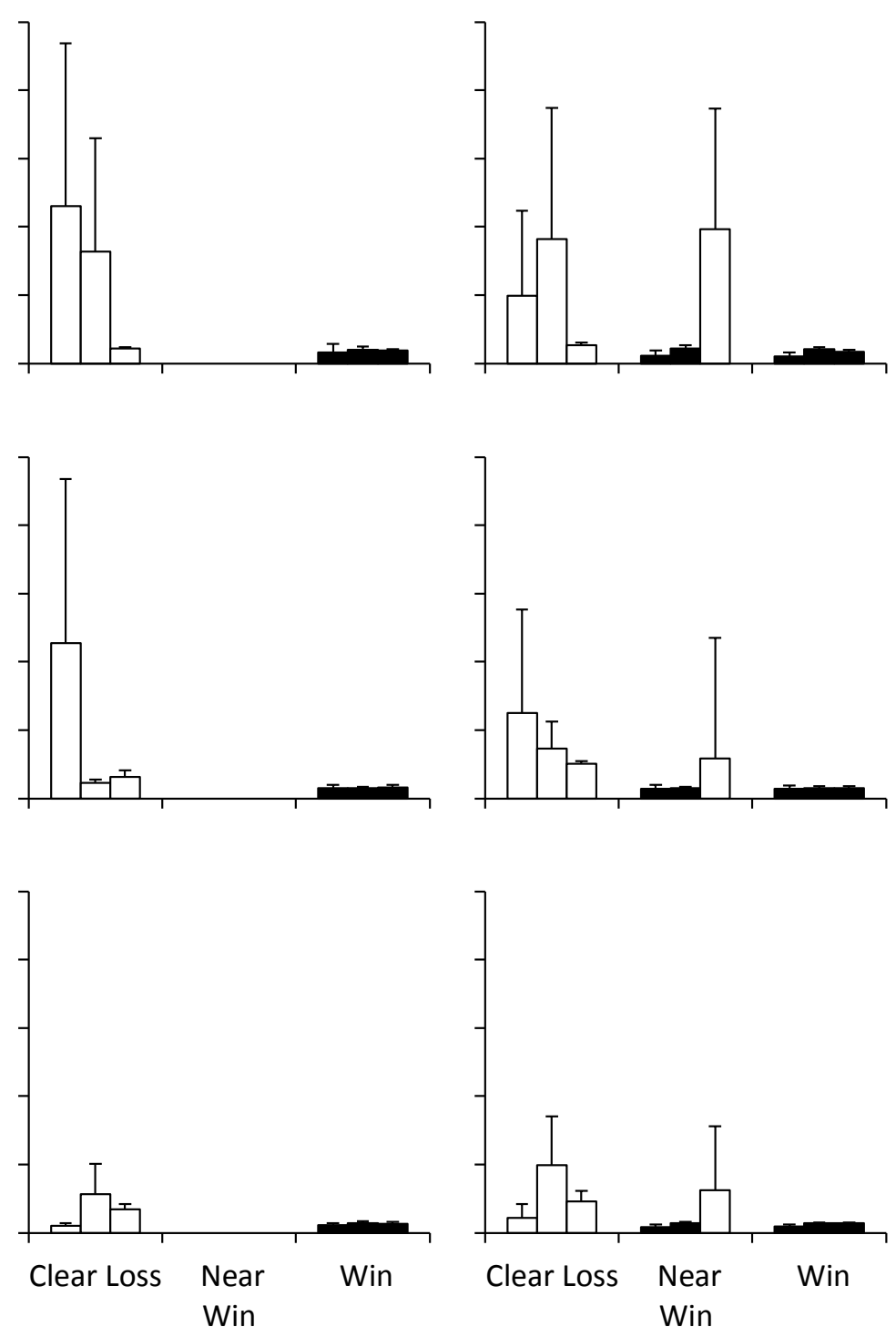

Gambling

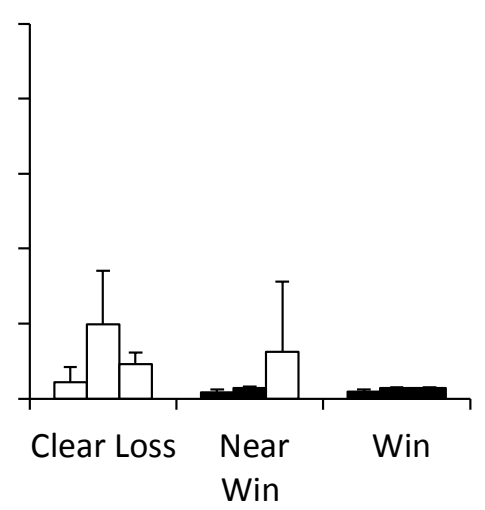

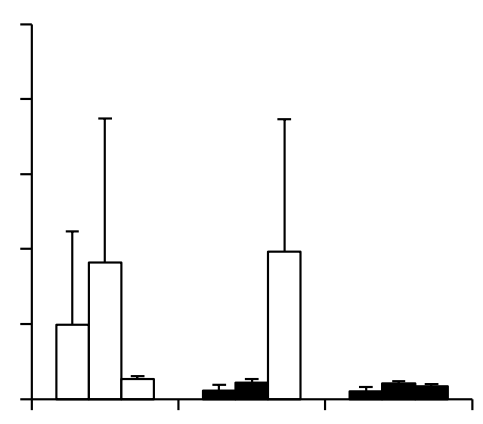

Trial Type

Figure 10. Interresponse times taken from the sample phase of each component as a function of trial type in Experiment 2. Median interresponse times are calculated for each session and means come from the last five sessions of each condition. White bars illustrate when the key would have been green and black bars illustrate when the key would have been red. Errors bars represent the standard deviation. 

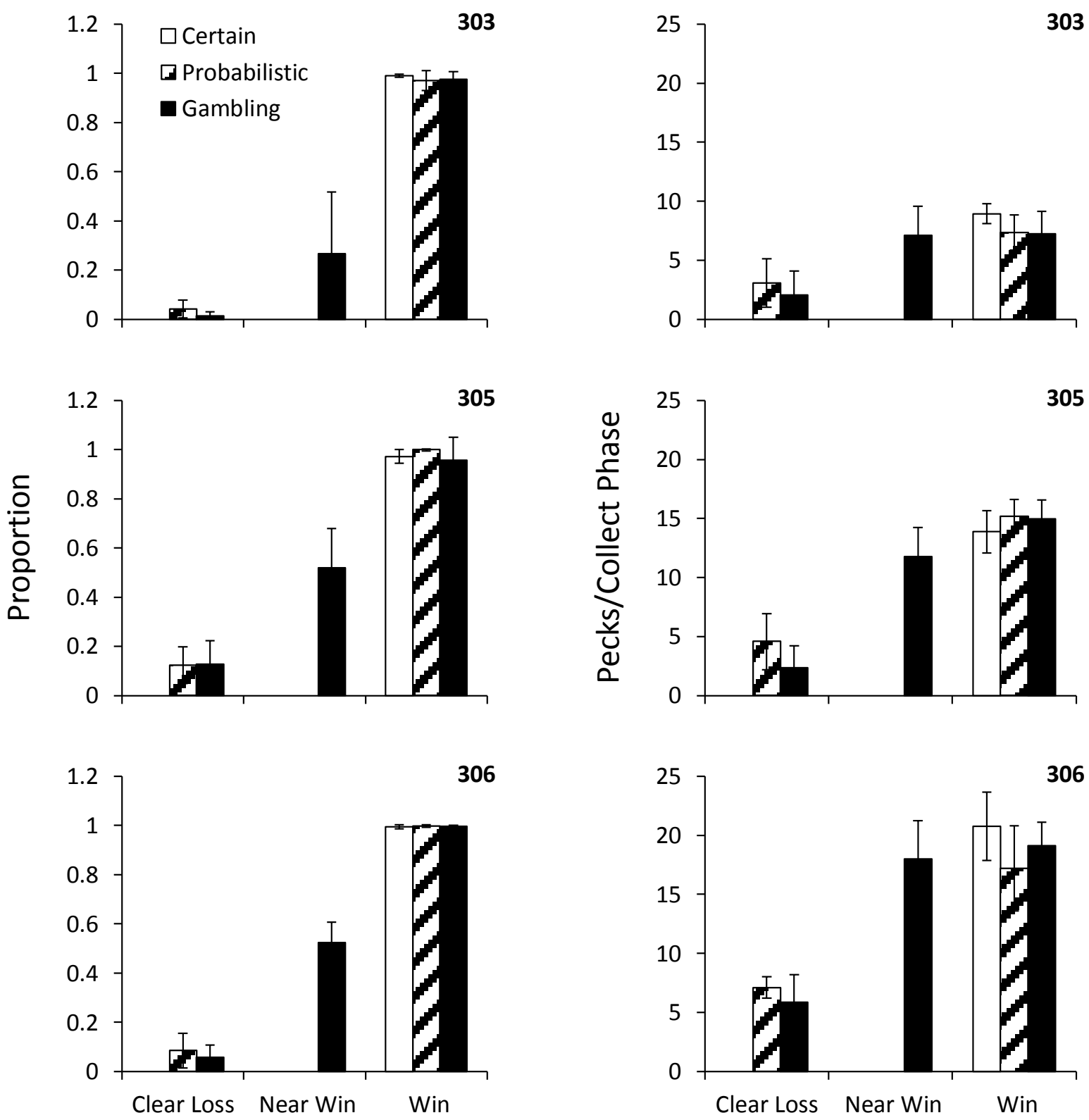

Trial Type 
Figure 11. Left column depicts mean proportion of trials where a peck occurred during the collect phase as a function of component and trial type in Experiment 2. Right column depicts the mean pecks per collect phase where at least one peck occurred as a function of component and trial type. White bars represent sample-phase responding from the Certain component, striped bars the Probabilistic component, and black bars the Gambling component. Bars show means calculated from pooling the last five sessions of each condition for a component. Error bars represent standard deviation. 

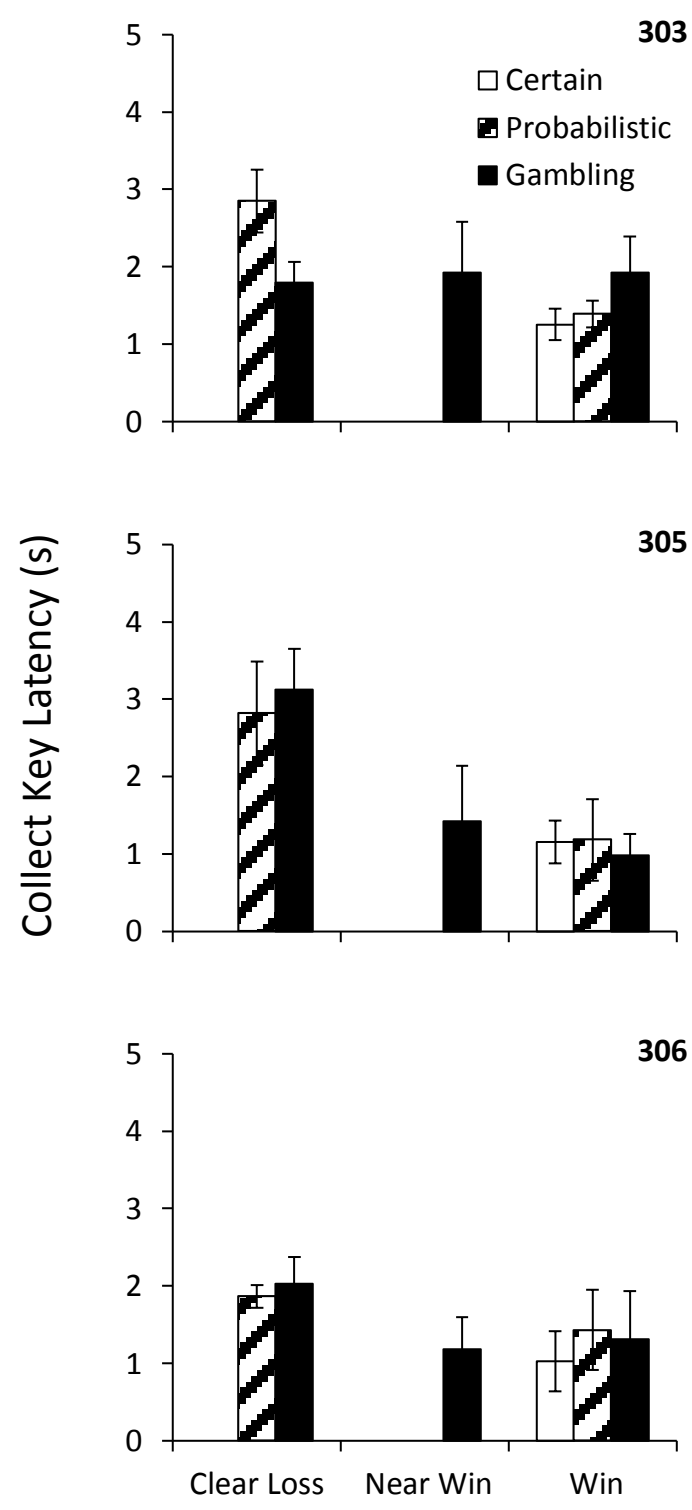

Trial Type

Figure 12. Mean latency to the first peck in the collect phase as a function of component and trial type in Experiment 2. Trials where no pecks occurred in the collect phase were omitted from this analysis. White bars represent the Certain component, striped bars the Probabilistic component, and black bars the Gambling component. Median latencies were obtained for each session and the mean for a condition was obtained from the last five sessions. Error bars represent standard deviation. 

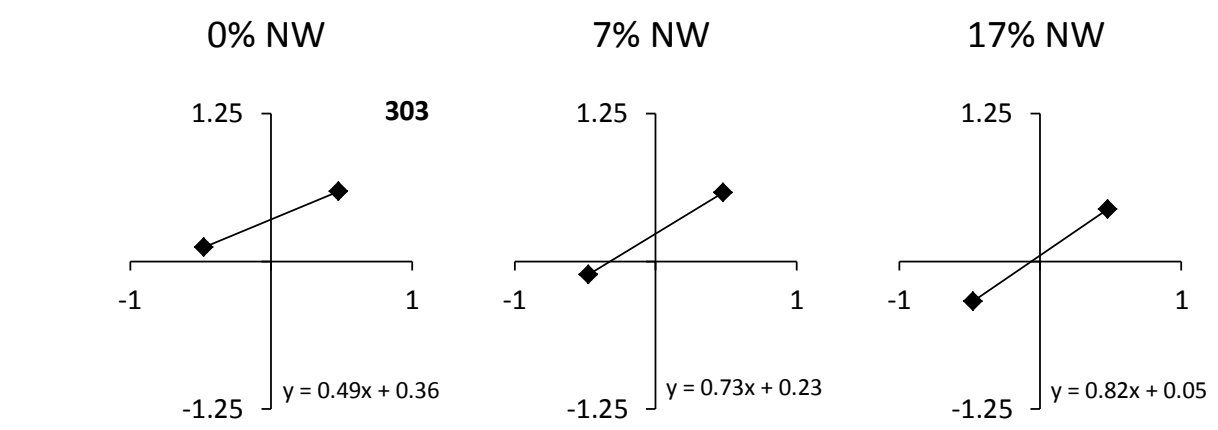

$33 \% \mathrm{NW}$

305
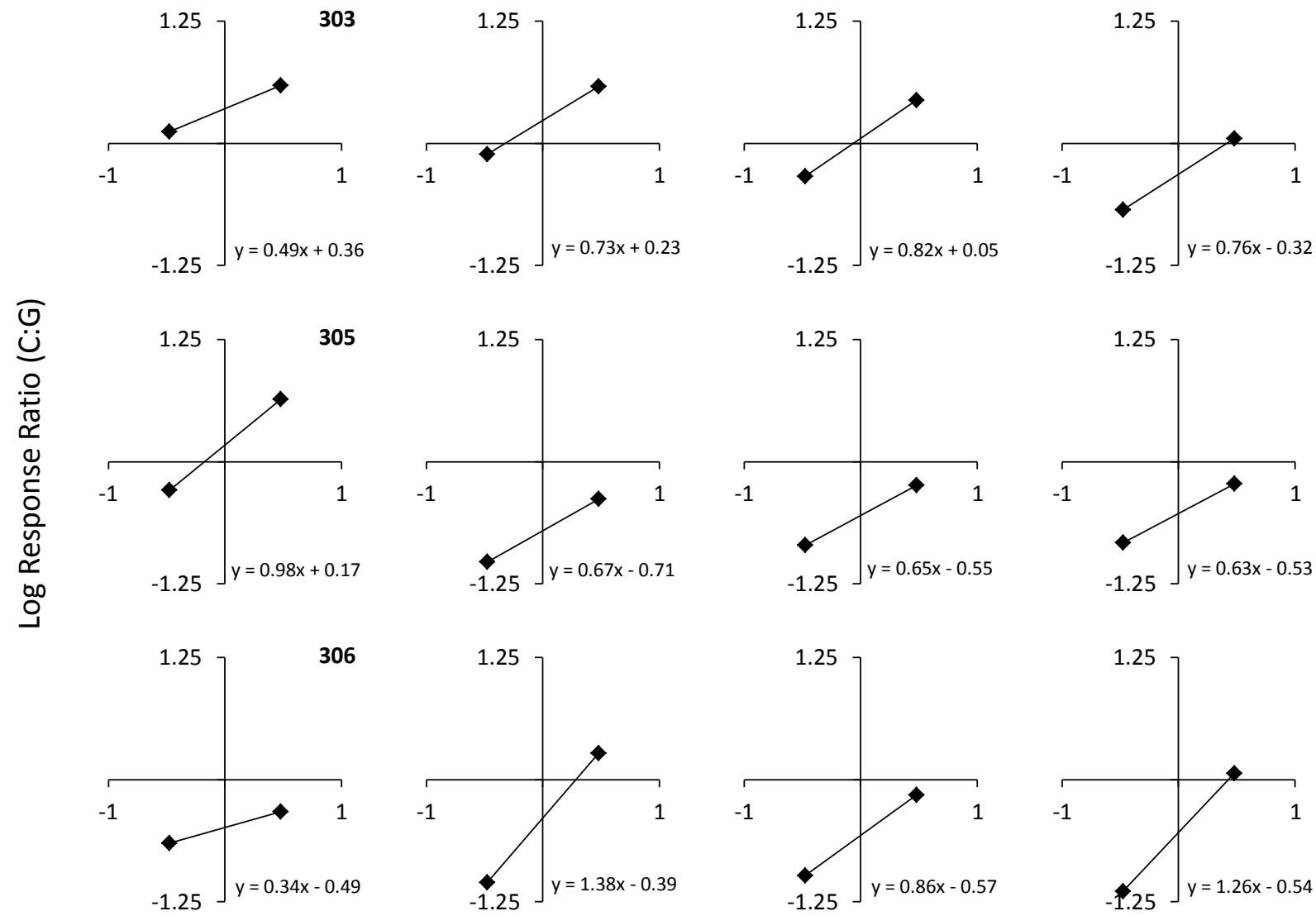

Log Relative Reinforcement Ratio

Figure 13. Matching law functions generated by Equation 1 for all phases (columns) for all subjects (rows) in Experiment 3. Data are shown as log response ratios as a function of log relative-reinforcement ratio. For the log response ratio, the letters represent components: certain (C) and gambling (G). Each data point represents a condition: 1:3 (leftmost) and 3:1 (rightmost). The line represents the line of best fit and its accompanying equation is shown in the bottom right of each panel. 

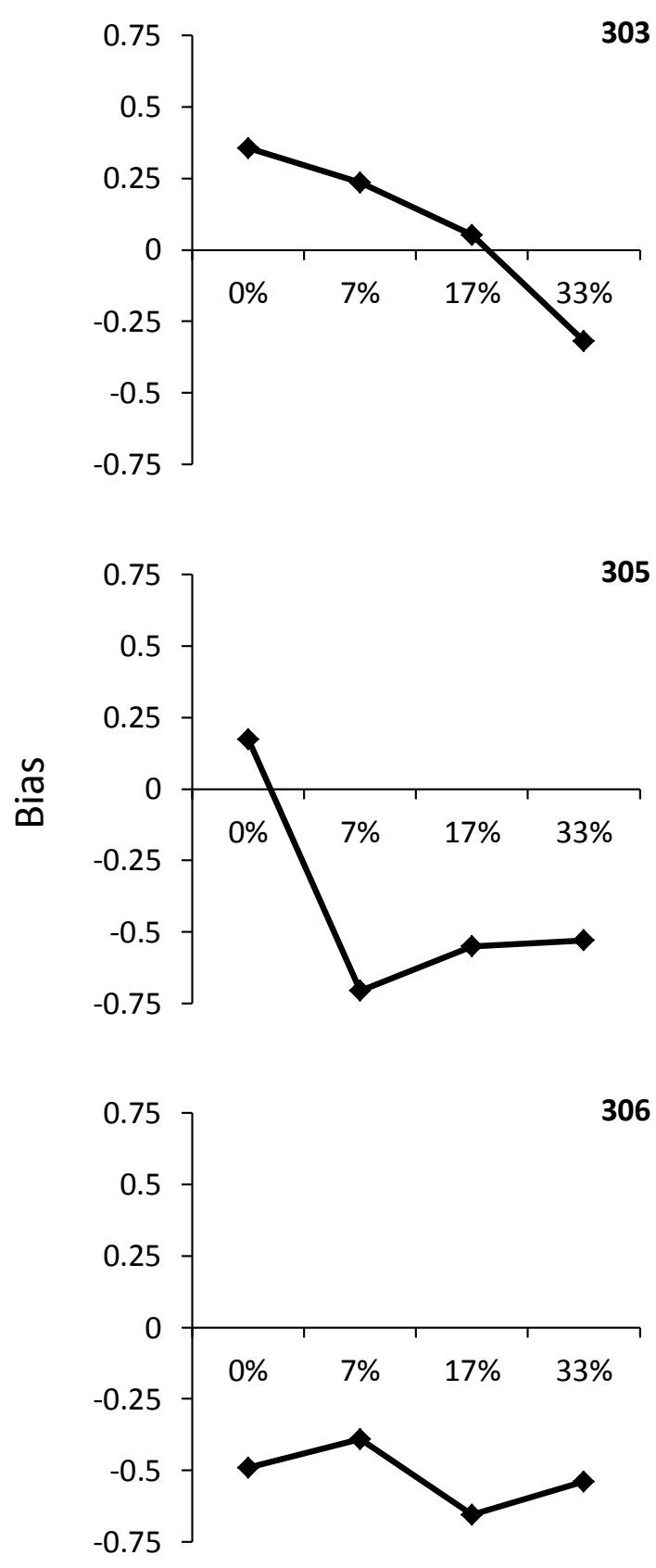

\section{Near-Win Probability}

Figure 14. Bias (y-intercept) parameters taken from each panel in Figure 13 and replotted as a function of near-win probability for each pigeon. Positive bias indicates when preference was for the Certain component and negative bias indicates when preference was for the Gambling component. 
Certain
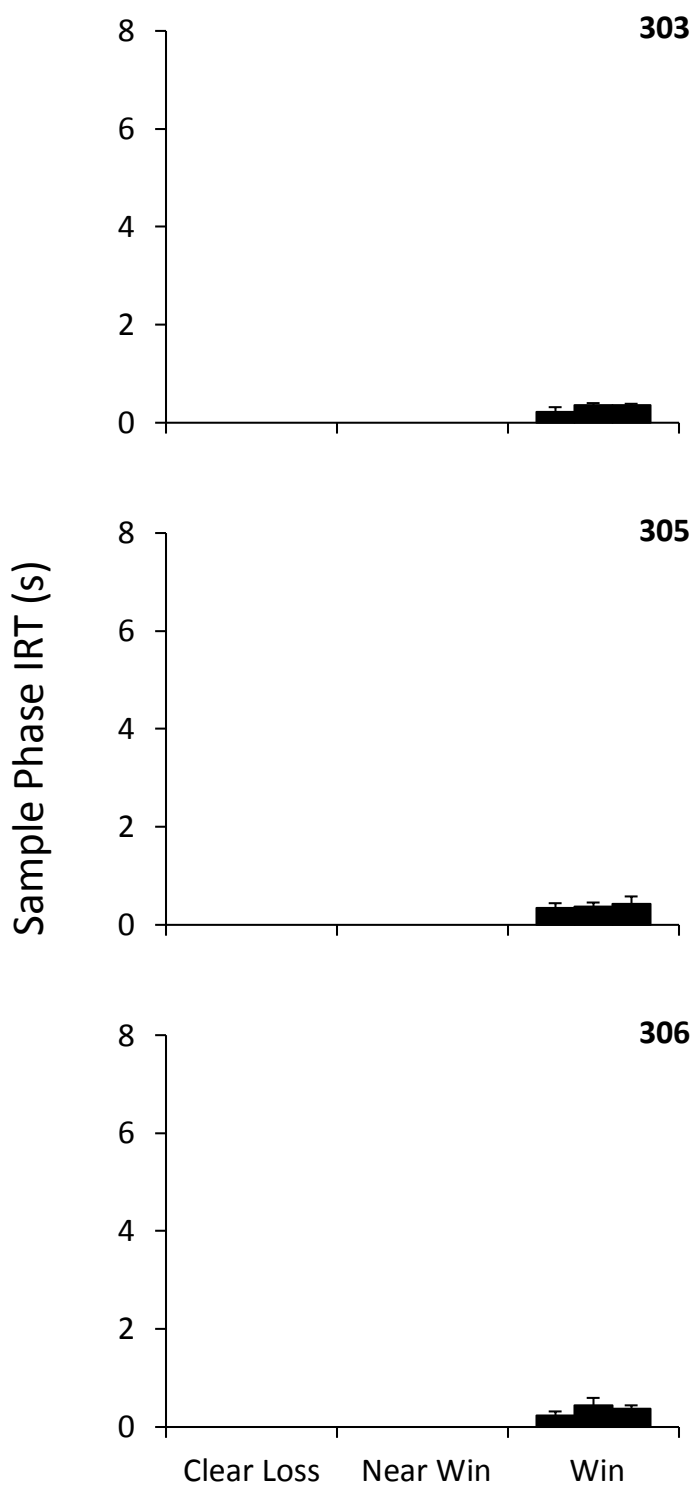

Gambling

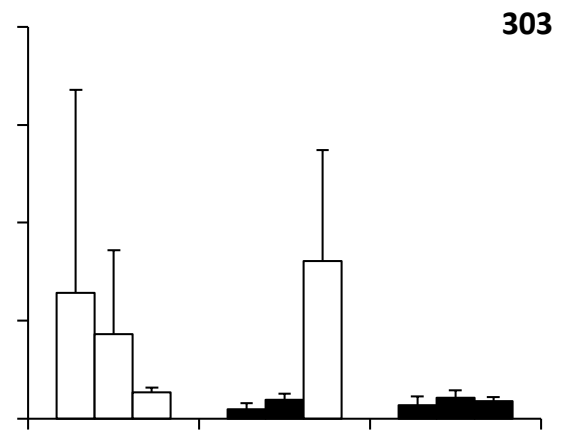

305
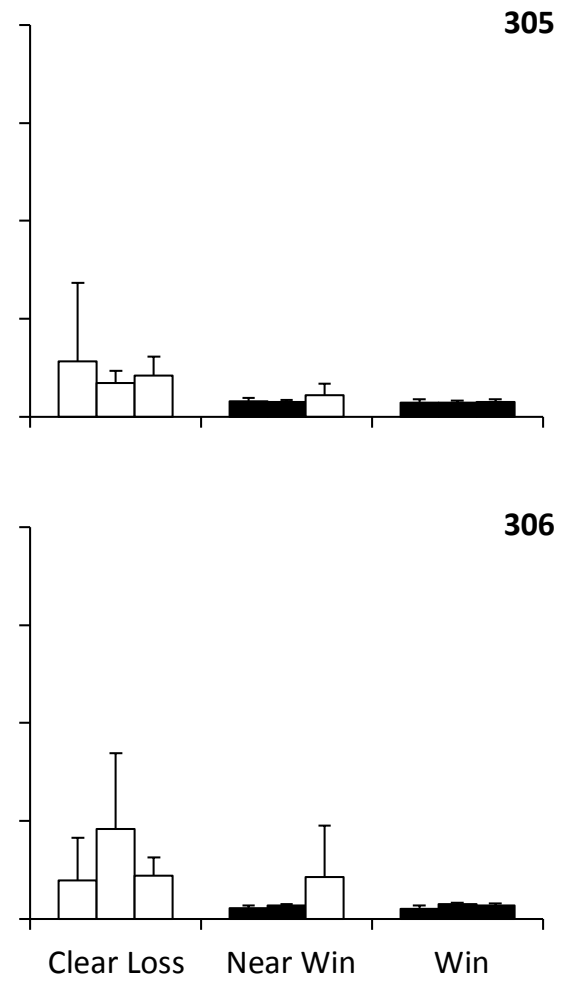

Trial Type

Figure 15. Interresponse times taken from the sample phase of each component as a function of trial type in Experiment 3. Median interresponse times are calculated for each session and means come from the last five sessions of each condition. White bars illustrate when the key would have been green and black bars illustrate when the key would have been red. Errors bars represent the standard deviation. 

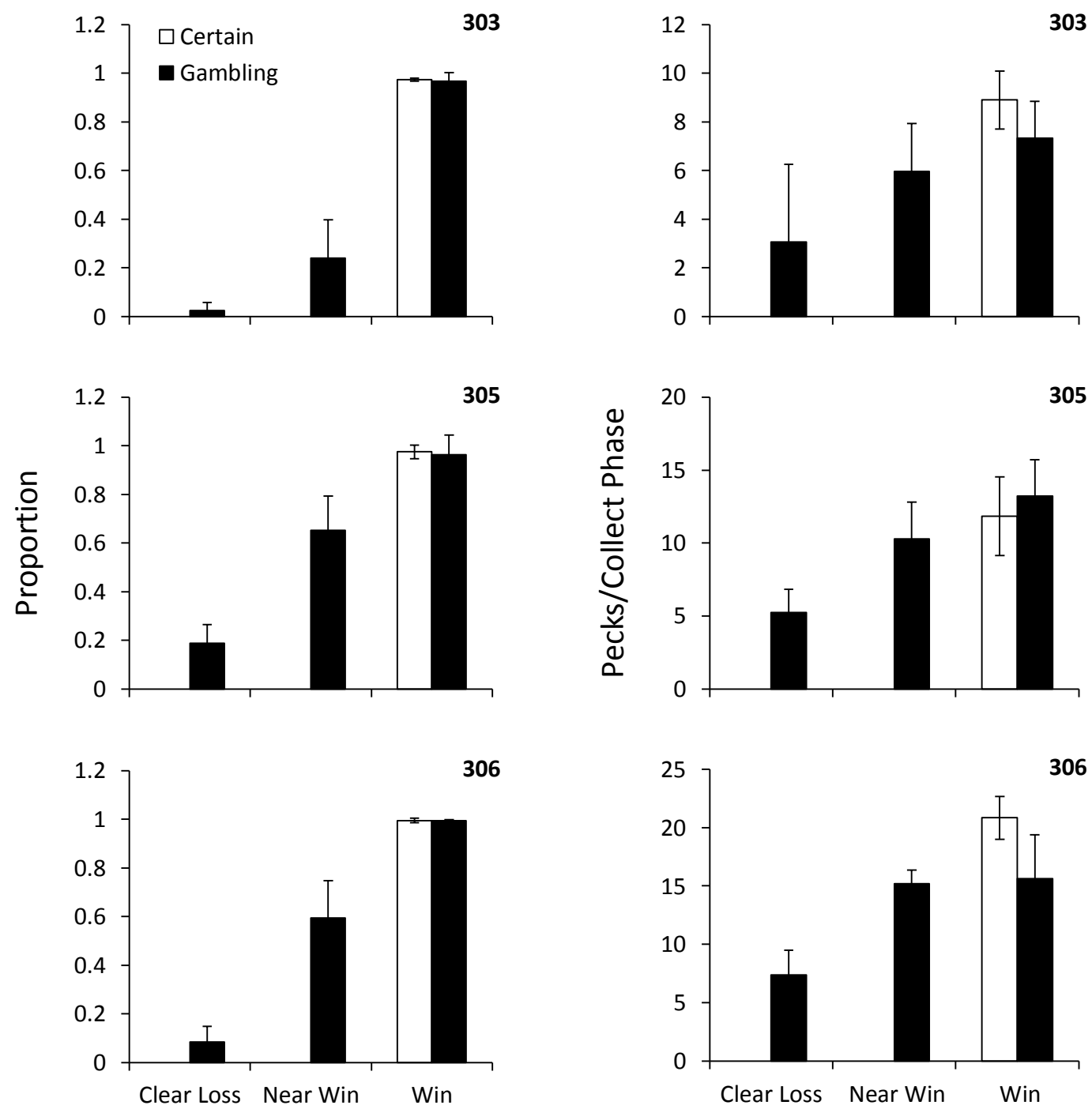

Trial Type

Figure 16. Left column depicts mean proportion of trials where a peck occurred during the collect phase as a function of component and trial type in Experiment 3. Right column depicts the mean pecks per collect phase where at least a single peck occurred as a function of component and trial type. White bars represent sample-phase responding from the Certain component and black bars represent the Gambling component. Bars show means calculated from pooling the last five sessions of each condition for a component. Error bars represent standard deviation. 

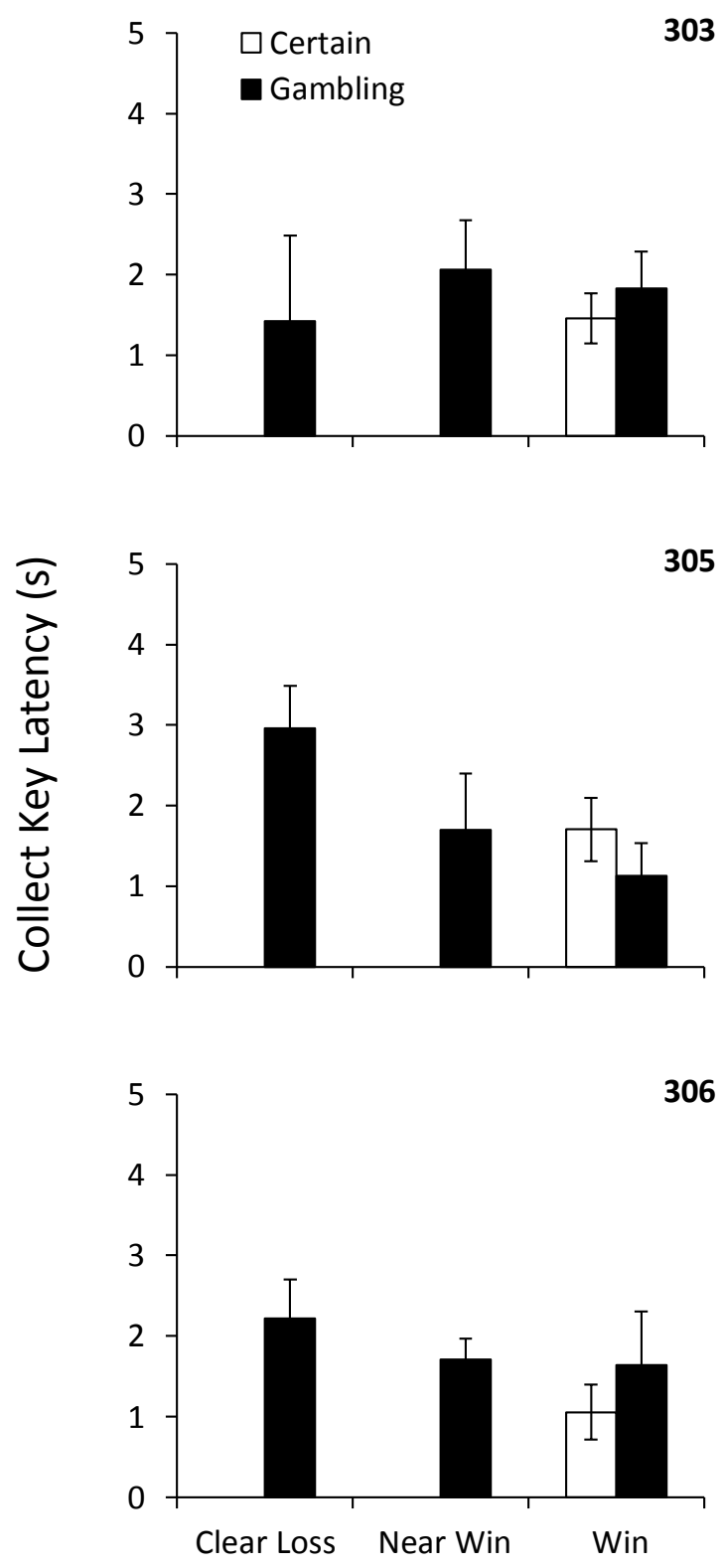

Trial Type

Figure 17. Mean latency to the first peck in the collect phase as a function of component and trial type in Experiment 3. Trials where no pecks occurred in the collect phase were omitted from this analysis. White bars represent the Certain component and black bars represent the Gambling component. Median latencies were obtained for each session and the mean for a condition was obtained from the last five sessions. Error bars represent standard deviation. 